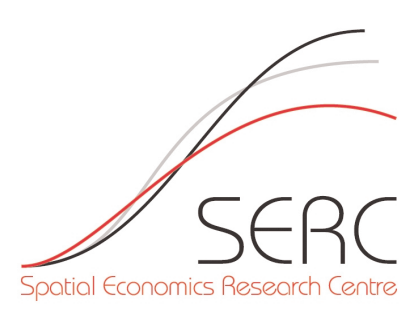

\title{
Urban Renewal after the Berlin Wall
}

Gabriel M. Ahlfeldt (LSE and SERC)

Wolfgang Maennig (University of Hamburg)

Felix J. Richter (University of Hamburg)

December 2013 
This work is part of the research programme of the independent UK Spatial Economics Research Centre funded by a grant from the Economic and Social Research Council (ESRC), Department for Business, Innovation \& Skills (BIS) and the Welsh Government. The support of the funders is acknowledged. The views expressed are those of the authors and do not represent the views of the funders.

(C) G.M. Ahlfeldt, W. Maennig and F.J. Richter, submitted 2013 


\section{Urban Renewal after the Berlin Wall \\ Gabriel M. Ahlfeldt* \\ Wolfgang Maennig** \\ Felix J. Richter**}

\section{December 2013}

* London School of Economics and Spatial Economics Research Centre

** University of Hamburg

\section{Acknowledgements}

We thank the Berlin Committee of Valuation Experts and the Senate Department for Urban De-velopment and the Environment for data provision. We also thank the conference participants of the 2013 SERC annual conference, the 2013 conference of the Verein fuer Sozialpolitik, and the 2013 ERSA conference and especially Paul Cheshire and Henry Overman for helpful comments and suggestions. 


\begin{abstract}
Urban renewal areas are popular but empirically understudied spatial planning instruments designed to prevent urban decline and induce renewal. We use a quasi-experimental research design to study the effects of 22 renewal areas implemented in Berlin, Germany, to increase housing and living quality in the aftermath of the city's division during the Cold War period. Our results suggest that the policy has helped reduce (increase) the number of buildings in poor (good) condition by 25\% (10\%). Property prices increased at an annual rate of $0.4-1.7 \%$ according to our preferred estimates. Evidence is weak at best, however, for positive housing externalities. More generally, our findings indicate that the efficiency of program evaluations for place based -policies using quasi-experimental methods increases with the number of targeted areas and areas that provide the counterfactual.
\end{abstract}

Keywords: Urban, renewal, revitalization, redevelopment, hedonic regression, quasiexperiment

JEL: D62, H23, R21, R31 


\section{Introduction}

Among the arguably most striking phenomena in contemporary cities is the simultaneous existence of urban decline and gentrification. One way to rationalize these apparently contradictory dynamics is to assume the existence of housing externalities, i.e., mutual quality related spillovers among properties in a neighborhood. If housing externalities exist, the attractiveness of a location depends on the simultaneous decisions of landlords and homeowners regarding the maintenance and upkeep of their properties (Rossi-Hansberg, Sarte, \& Owens, 2010). As good design and poor maintenance of surrounding buildings make an area relatively more or less attractive to different household types and can lead to sorting, housing externalities can affect the profitability of investments in the design and upkeep of a building. As an example, we may observe a downward spiral in which poor maintenance and the flight of affluent households mutually reinforce one another and lead to urban decline. In an otherwise similar neighborhood, investments in the building stock and the attraction of affluent households could become mutually reinforcing and lead to gentrification. As with many spatial outcomes, there is a possibility that multiple spatial equilibrium configurations exist, and privileged and disadvantaged neighborhoods result from a Krugman $(1991,1994)$ type historical accident. Given the potential for multiple equilibria and that no economic market exists where housing externalities could be traded, it is easy to rationalize government intervention.

There are numerous sizable programs targeting neighborhoods in need around the world. In the U.S. the Community Development Block Grant (CDBG) provides between $\$ 3$ and $\$ 10$ bill. each year to cities and local administrations to improve conditions in low income urban areas (Brooks \& Phillips, 2007). Another example is the Home Investment Partnership (HOME) program, which supports affordable housing with approximately $\$ 2$ bill. per year. In Germany, the budget for various urban development programs ("Städtebauforderung"), which are typically jointly financed by the federal government and the federal states, amounts to approximately $€ 350$ (\$453.1) mill. to $€ 500$ (\$647.3) mill. per year (Bundesinstitut für Bau-, Stadt-, und Raumforschung (2009)). ${ }^{1}$ One justification for such public expenditures rests on anticipated positive and self-reinforcing housing externalities, i.e., the hope that subsidies for the renovation of a property will benefit others in addition to the

\footnotetext{
1 Aggregate renewal financing data at the European level are not available.
} 
respective owner or landlord. Complementary arguments have been the preservation of cultural heritage or an increase in the consumption value of cities that helps to attract high skilled workers (Glaeser, Kolko, \& Saiz, 2001).

To date, surprisingly little evidence is available on the impact these policies have on housing market outcomes. One reason for this lack of evidence might be that separating the effects of policies designed to promote housing externalities from other forces that (re)shape the structure and attractiveness of cities and neighborhoods is a challenging task. For one thing, housing externalities are not tradable goods. As such, it is not possible to value them based on observable market prices. One established way of addressing this problem is to assume a spatial equilibrium in which housing prices must offset all locational advantages and disadvantages, including the policy in question (Roback, 1982; Rosen, 1974). ${ }^{2}$ Various policies have been studied based on the associated capitalization effects in a long tradition that dates back to Oates (1969) at least. ${ }^{3}$ Moreover, the task is a derivative of the broader problem in the social sciences of separating the effect of treatments form correlated effects. In a spatial context, the challenge is to separate the policy effect (the treatment) from a variety of other factors that affect the attractiveness of a location, many of which are unobserved. Quasi-experimental methods have recently gained popularity as a means to control for unobserved factors that impact house price trends (Ahlfeldt \& Kavetsos, 2013; Dachis, Duranton, \& Turner, 2012; Gibbons \& Machin, 2005). In this approach, a counterfactual for a group of treated properties (exposed to the policy) is established via the comparison of house price trends with a control group. Key to the credibility of such approaches is the appropriateness of the identifying assumptions that a) the control group itself is unaffected by the treatment and b) the control group in the absence of an intervention would have followed exactly the same trend as the treated.

Our analysis employs such a quasi-experimental research design to identify the effects of some substantial urban renewal policy efforts in Berlin, Germany that began in the early 1990s. The policy was aimed at promoting the recovery of neighborhoods that were found to have suffered particularly severely during the long lasting period of division. We follow

2 See Lucas and Rossi-Hansberg (2002) and Ahlfeldt et al (2012) for recent urban equilibrium models.

3 See Celini, Ferreira and Rothstein (2010), Dehring, Depken, \& Ward (2008), Brunner, Sonstelie, \& Thayer (2001), Brunner, and Sonstelie (2003) for a recent examples. 
the evolution of these neighborhoods over more than two decades, paying particular attention to establishing a valid counterfactual via appropriate control groups and isolating policy related housing externalities from other determinants of house prices.

To our knowledge, we are only the second, after Rossi-Hansberg et al. (2010) [hereafter $\mathrm{RH}]$, to provide a rigorous evaluation of revitalization policies. $\mathrm{RH}$ investigate property prices in and around four renewal areas ${ }^{4}$ and one control area, which was initially considered but ultimately excluded from the program in Richmond, Virginia to detect housing externalities. Their results indicate that housing externalities exist but diminish relatively steeply in distance, approximately 50\% every 1000 feet (RH 2012, p. 487). Equally important, they estimate that house prices in the designated areas rose between 2 and 5\% per year during the renewal period, which equates to a return of 2 to 6 USD per dollar invested. Their results, thus, strongly indicate that urban renewal programs promote positive housing externalities and might be efficient instruments to increase welfare in neighborhoods in need. Despite the methodological rigor of their analysis, there is an evident need for complementary evidence to conclude on the generalizability of the case. This is especially true given that RH establish their counterfactual via a singular control area. As such, their finding might be sensitive to idiosyncratic characteristics of that area, which could influence the counterfactual price trend, but are difficult to anticipate. In short, we complement RH's findings by analyzing a larger policy experiment over a longer period. We make use of a relatively large pool of treated areas and potential control areas to obtain credible estimates for the average effect across the treated areas and to evaluate the sensitivity of the estimates to the selection of a more limited number of treated and control areas.

Berlin offers a unique institutional setting for an analysis of revitalization policies due to the $20^{\text {th }}$ century history of the city. For several decades, the former capital of Germany suffered from either economic isolation (West Berlin) and loss of market access (Redding \& Sturm, 2008) or transformation into a non-market economy (East-Berlin), both of which severely affected the economic health of the city. After reunification in 1990, the adverse economic performance was mirrored by a poor physical condition of the housing stock,

4 Definitions and notation vary. Throughout this article, we will try to stick to the term renewal area, however, the terms redevelopment or revitalization area are often used interchangeably. 
especially so in the eastern part (Berlin, 1992), p. 16). In response to this situation, 22 out of 39 originally proposed renewal zones were designated between 1993 and 1995 as target areas for a renewal program. ${ }^{5}$ Until late 2009 (the period of the last official report on the renewal program), as much as €1.8 Bill. (\$2.34 Bill.) had been spent on these areas.

Our quasi-experimental research design compares property price trends within these 22 selected conservation areas over the period from 1990 to 2012 to various counterfactuals. We consider the runner-up areas ("Untersuchungsgebiete") not selected for the program as a control group for comparison but also make use of other control groups that are close to the treated areas either in spatial or socio-economic terms. ${ }^{6}$ Using these counterfactuals, we establish a composite renewal effect, which consists of an increase in the structural value of renovated properties and an increase in locational value due to the renovation of adjacent properties, i.e., a housing externality. One attractive feature of our data set is an indication of a property's physical condition at the time of transaction. We exploit this feature to determine the housing externality effect by exclusively focusing on properties in good condition. The rationale is twofold. First, by holding internal quality constant, our estimated treatment effects only capture appreciation related to the renovation of surrounding properties, i.e., an (housing) external(ity) effect. Second, we argue that properties in good condition at the time of the transaction are unlikely to be renovated immediately following the transaction, and hence that renovation incentives (subsidies and tax deductions) do not (or only to a limited extent) capitalize into the transaction prices. We complement this approach to measuring housing externalities with an analysis of spatial spillovers into areas just outside the treated areas. Previewing our findings, our results indicate that the policy led to a significant upgrade of the housing stock and a general appreciation of the properties in targeted areas but not to the pure increase in site value due to housing externalities for which one may have hoped.

In addition to adding important evidence to the sparsely developed literature on the economic effects of revitalization policies (e.g. Clay, 1979; Rossi-Hansberg et al., 2010) and housing externalities (e.g. Ahlfeldt \& Kavetsos, 2013; Ahlfeldt \& Maennig, 2010; Koster \&

\footnotetext{
5 The First Berlin Renewal Program (Erstes Gesamtberliner Stadterneuerungsprogramm).

6 The fragmentation of some of the 39 initial investigation areas results in 22 self-contained zones that were treated as well as another 22 zones that remained untreated.
} 
Van Ommeren, 2013; Rossi-Hansberg et al., 2010; Schwartz, Ellen, Voicu, \& Schill, 2006), our analysis connects to a more general research strand in urban economics that examines the amenity value of cities (e.g. Albouy, 2009, 2012; Blomquist, Berger, \& Hoehn, 1988; Gabriel \& Rosenthal, 2004; Gyourko \& Tracy, 1991; Tabuchi \& Yoshida, 2000) or neighborhoods within cities (e.g. Ahlfeldt, 2011; Brueckner, Thisse, \& Zenou, 1999; Carlino \& Coulson, 2004; Cheshire \& Sheppard, 1995; Ioannides, 2003).7 This literature has argued that there has been a re-orientation towards attractive central cities, especially among high-skilled young professionals, the so called creative class (Florida, 2002). The consumption value of cities has therefore become increasingly important for the attraction of a highly skilled labor force and, hence, the economic success of cities (Carlino \& Saiz, 2008; Glaeser et al., 2001). Our findings inform this literature on whether revitalization policies and other neighborhood polices such as historic preservation may contribute to the development of targeted neighborhoods, ${ }^{8}$ or whether other factors such as transport affordability (LeRoy \& Sonstelie, 1983), housing cycles (Brueckner \& Rosenthal, 2009) or natural amenities (Lee \& Lin, 2012) are more important determinants of gentrification. Our results also complement the analysis by Ahlfeldt et al. (2012), who estimate a general equilibrium model of simultaneous household and firm location using exogenous variation that stems from the rise and fall of the Berlin Wall. Our results provide further evidence that the fundamental re-orientation to the pre-WW II equilibrium the city experienced after the fall of the Berlin Wall is unlikely to be explained by the renewal policies and likely attributable to economic agglomeration and dispersion forces. Finally, our results inform the program evaluation literature more generally in that successful identification of placebased policy effect using quasi-experimental methods may critically depend on sufficiently large number of treatment and control areas.

7 This study complements research examining the effects of spatial density on the productivity of workers and firms (e.g. Ahlfeldt et al., 2012; Ahlfeldt \& Wendland, 2013; Ciccone, 2002; Ciccone \& Hall, 1996; Glaeser, Hedi, Jose, \& Andrei, 1992; Glaeser \& Mare, 2001; Rauch, 1993; Rosenthal \& Strange, 2001)

8 A growing body of literature has investigated the capitalization effects of historic designation, both on designated buildings and properties near designated buildings (e.g. Asabere, Huffman, \& Mehdian, 1994; Clark \& Herrin, 1997; Coulson \& Lahr, 2005; Coulson \& Leichenko, 2004; Koster, Van Ommeren, \& Rietveld, 2012; Lazrak, Nijkamp, Rietveld, \& Rouwendal, 2010; Leichenko, Coulson, \& Listokin, 2001; Listokin, Listokin, \& Lahr, 1998; Noonan \& Krupka, 2011; Schaeffer \& Millerick, 1991). 
The remainder of the article is organized as follows: Section 2 introduces into the institutional setting. Sections 3 and 4 present the empirical strategy and results. The final section summarizes our findings and concludes.

\section{Background}

After World War II, the building stock in Berlin was fairly degenerated. Especially in the eastern part, which was part of the former German Democratic Republic (GDR), many buildings had not or had only been insufficiently renovated until the unification due to tight budget constraints. Additionally, private incentives to rebuild housing stock were low, as private real estate ownership was not encouraged in the GDR and rents were frozen at a low level since 1945. These developments resulted in an overall poor condition of the building substance of original housing stock and inner city district centers, including massive vacancies, and an increased need for renovation after unification in 1990. Moreover, the political mood after the unification of East and West Germany facilitated large scale public funding. Among other programs, these developments resulted in the First Berlin Renewal Program.

The main instrument to overcome these problems was the initiation of a group of urban renewal areas, which are eligible for public funding and support according to specific rules. The location, shape, and structure of a renewal area are determined in a political decision process that involves several steps: First, the districts of Berlin and the Senate initiate a search for hotspots of urban decline, the so called 'investigation areas', to identify potential renewal areas. In depth analyses of the social structure in the respective areas are then commissioned, which encompass possible revitalization concepts and recommendations on size and position of the potential renewal areas. Finally, the Senate of Berlin officially designates the renewal areas (Maennig, 2012).

In July 1992, the Senate of Berlin initiated 39 investigation areas. In 1993, 1994, and 1995, 22 renewal areas were officially designated, with an overall area of approximately 8.1 square kilometers, 5,723 plots, and approximately 81,500 dwelling units, with an average population of 5,000 residents per renewal area (Senat Berlin, 2001). ${ }^{9}$

9 In Richmond, the object of the RH (2012) analysis, the four targeted areas had an average population of 1900 residents and on average 1,000 housing units. 
The Berlin program is characterized by two main phases: In the post-unification phase between 1992 and 2002, massive vacancies, and very poor building substance were the driving factors of the renewal program. By 2000 , already more than $50 \%$ of the housing units in the renewal areas had been modernized (Berlin, 2005). Private investments in the building stock have been supported though tax reductions, loans, cash advances and further financial support. In the post-2002 phase, due to the progress made during the postunification phase and an increasingly tight public budget, the focus changed: It was set to improvements of the social infrastructure and living quality of the neighborhood. Private modernizations are no longer co-financed through public investments, but significant tax abatements remain as an implicit subsidy. ${ }^{10}$

As indicated above, most of the designated renewal areas are located in the former eastern part of Berlin. Additionally, the five renewal areas in the former West Berlin are much smaller than their eastern counterparts. Only approximately $6 \%$ of the housing units inside the renewal areas were located in the western part of Berlin, reflecting that West Berlin was in a significantly better economic situation after the fall of the Berlin Wall.

Until 2009, the expenses comprised more than 1.8 billion $€$ (2.3 billion US\$) in public investments, amounting to approximately 880 million $€$ (1.13 billion US\$) for modernization and reinstatement, and approximately 546 million $€$ (730 million US\$) for expenses on infrastructure and social environment. The remaining disbursements consist of preparation costs (€75 mill. / \$97 mill.), allowances ( $€ 115$ mill. / \$150 mill.), other regulatory measures including compensations (€181 mill. / \$235 mill.), and other building measures (€63 mill. / \$81 mill.).11 On single renewal area level, the average expenses are approximately 80 million $€$ (102 million US\$), translating into per capita expenses of $€ 16,000$ $(\$ 20,600)$ distributed over a period of some 15 years. This compares to per area payments of $\$ 3.5$ mill. and per capita expenses of $\$ 1,800$ in Richmond in a period of four years. Currently, 19 of the 22 considered renewal areas have been released from their renewal sta-

10 Generally, modernization costs for own use or renting can be amortized completely over a runtime of 10 to 12 years. For a detailed account of the regulations, compare $\S 154$ and 177 in the building law code (BauGB) and $\S 7 \mathrm{~h}, 10 \mathrm{f}$, and 11a of the income tax law code (EStG).

11 See (Berlin, 2010), where the local administration (Senatsverwaltung Berlin) provides detailed budget accounting information for the different time periods. More up-to-date figures are not yet available to the best of our knowledge. 
tus; Figure 1 in the data section shows the geographic locations of the renewal and investigation areas in Berlin. ${ }^{12}$

\section{Empirical Strategy}

While assessing whether significant price trends exist within renewal areas relative to other areas is empirically straightforward, separating the causal effects of the policy from correlated effects and distinguishing between "internal" and "external" (via the housing externality) capitalization effects is more challenging. First, the locations where these policies operate are not random and likely correlated with specific location characteristics. Second, the characteristics, when unobserved, may not only affect the level of property prices at a given locality but also the trends they follow. Third, housing quality and especially exterior housing quality is difficult to observe. Our identification strategy engages with these challenges and makes use of housing quality indicators that are typically difficult to obtain. Before we present our actual empirical specification, we abstract from some of the identification issues to introduce the basic nature of the treatment effect we estimate.

\subsection{Identification}

Let us assume we observe a property, the maintenance levels of which are constant within a neighborhood and depend on a housing subsidy $S$. Within a neighborhood, the housing subsidy policy is uniform.

At any given location, the value of a property $(P)$ depends on the maintenance level $(I)$, a (housing) externality (E), which depends on the maintenance level in the neighborhood and the amenity level $(L)$ of the neighborhood, and the overall macroeconomic conditions that are invariant across neighborhoods $(Y)$. For now, we assume that the policy does not impact neighborhood quality except through a housing externality:

$$
P=f(I(S), E(I(S)), L, Y)
$$

12 See Table A1 in the technical appendix for details on designation date, district, and expiration of the renewal areas. An overview of the area is shown is in Figure 1; a snapshot providing more detailed graphical information can be found in Figure A1 in the appendix. 
For simplicity, we assume that the externality is simply the aggregate of individual maintenance levels at all locations within the neighborhood, i.e., there is no spatial decay within the neighborhood. In a linear neighborhood aligned along one dimension $D$ from zero to one, we can then simply write:

$$
E(D)=\int_{0}^{1} I(D) d(D)=I
$$

Taking the total derivative we can rewrite the price equation as follows:

$$
d P=\left(\frac{\partial P}{\partial I(S)}+\frac{\partial P}{\partial E(S)}\right) d I(S)+\frac{\partial P}{\partial L} d L+\frac{\partial P}{\partial Y} d Y
$$

Or:

$$
d P=\left(\frac{\partial P}{\partial I}+\frac{\partial P}{\partial E}\right) \frac{\partial I}{\partial S} d S+\frac{\partial P}{\partial L} d L+\frac{\partial P}{\partial Y} d Y
$$

To identify the effect of the policy on property value, we essentially employ the differencein-difference methodology that compares the value of properties at different points in time (first difference $\Delta$ ) and at different locations (second difference $d$ ). We assume that a change in policy $\Delta S$ only becomes effective in a treatment neighborhood (T), but not in an otherwise comparable control neighborhood $(C)$ that is subject to the same macroeconomic shocks $\left(\Delta Y^{T}=\Delta Y^{C}\right) .13$

Our treatment effect can be described as follows:

$$
\beta=\left(P(S=1)^{P O S T}-P\left((S=0)^{P R E}\right)^{T}-\left(P(S=0)^{P O S T}-P(S=0)^{P R E}\right)^{C}\right.
$$

Or:

$$
\beta=\Delta P^{T}-\Delta P^{C}
$$

If we assume $L$ to be time invariant at any location, i.e., $\Delta L=0$, our treatment effect is defined as follows:

13 In the empirical implementation, we introduce a buffer around the treated areas to ensure that the control group is not affected by the treatment through spillover effects. 


$$
\beta=\left(\left(\frac{\partial P}{\partial I}+\frac{\partial P}{\partial E}\right) \frac{\partial I}{\partial S} \Delta S+\frac{\partial P}{\partial Y} \Delta Y\right)^{T}-\left(\left(\frac{\partial P}{\partial I}+\frac{\partial P}{\partial E}\right) \frac{\partial I}{\partial S} \Delta S+\frac{\partial P}{\partial Y} \Delta Y\right)^{C}
$$

Or:

$$
\beta=\left(\frac{\partial P}{\partial I}+\frac{\partial P}{\partial E}\right) \frac{\partial I}{\partial S}, \quad \text { where } \Delta S=\left\{\begin{array}{l}
1 \text { if treated } \\
0 \text { if control }
\end{array}\right.
$$

There are important implications for our empirical strategy that aims to estimate $\beta$. First, as in any quasi-experimental policy evaluation, the treatment effect only reveals the unbiased policy effect operating via $I$ under the assumption that the control group in the absence of the policy would follow the same trend $\left(\Delta Y^{T}=\Delta Y^{C}\right)$. An appropriate definition of a control group is therefore crucial for the identification. Second, given an appropriately defined control group, the difference-in-difference coefficient identifies a composite effect determined by the impact of the policy on maintenance levels in the neighborhood $((\partial I / \partial S) \Delta S)$, and the valuation of internal quality $(\partial P / \partial I)$ and the housing externality $(\partial P / \partial E)$ if the effect of internal housing quality is not held constant in an empirical model. Third, to the extent that the interior quality effect can be held constant empirically $((\partial P / \partial I) \Delta S=0)$, the treatment reflects the externality effect caused by the policy $(\beta=$ cy $(\beta=(\partial P / \partial E)(\partial I / \partial S))$. With the data we have at hand, we are able to hold the interior quality effect constant by restricting the transactions sample to properties in good condition.

\subsection{Renewal Effects}

Baseline specification

We use a combination of hedonic (Rosen, 1974) and difference-in-difference methods to estimate the treatment effect discussed above. Specifically, we aim at estimating a series of time specific $\beta_{V}$ parameters, where $V$ indicates the number of years that have passed since designation. To estimate these parameters of interest, we estimate the following empirical specification:

$$
\begin{aligned}
\log P_{i t} & =\alpha_{1} T_{i}+f\left(T_{i} \times V_{i t}\right)+\delta\left(T_{i} \times A_{i t}\right) \\
& +\sum_{k} \gamma_{k} X_{k i t}+\sum_{l} \gamma_{l} L_{l i}+\sum_{t} \sum_{g}\left(\gamma_{g t} G_{i} \times \varphi_{t}\right)+\sum_{t} \varphi_{t}+\sum_{n} \mu_{n}+\varepsilon_{i t},
\end{aligned}
$$


where $P_{i t}$ is the price at which a property $i$ is sold at time $t$. The central elements of this specification are an indicator variable $T$, which denotes whether a property falls within one of the renewal areas we investigate ( $T=1)$ or into the control area $(T=0)$, and the function $f\left(T_{i} \times V_{i t}\right)$, which captures interaction effect of being located within one of the renewal areas and the number of years this area has been designated $(V)$. We discuss the functional forms we use in depth later in the text after providing a description of and a rationale for the control variables used.

For a number of renewal areas, we observe transactions after their release from designation status $\left(A_{i t}=1\right)$. We control for a potential capitalization effect via the interaction term $\left(T_{i} \times A_{i t}\right) . X_{k}$ and $L_{l}$ are observable property and location characteristics discussed in the data section and $\gamma_{k}$ and $\gamma_{l}$ are the respective implicit prices. We control for otherwise unobserved time-invariant location characteristics via a fixed effects $\mu_{n}$ defined for 323 traffic cells. ${ }^{14}$ Standard errors $\left(\varepsilon_{i t}\right)$ are clustered at the same level. Macroeconomic factors that are assumed to be invariant across the treatment and control groups are captured by year fixed effects $\varphi_{t}$.

In addition to controlling for year effects and time-invariant location characteristics, we further allow for time-variant implicit prices $\gamma_{g t}$ for some time-invariant location characteristics $G_{i}$ by means of interaction terms with the year effects. The rationale for including these variables is that, unlike in real experiments, assignment to treatment and control groups is unlikely to be entirely random in a policy experiment, no matter how carefully treatment and control groups are matched to each other. If some of the attributes in which the treated and non-treated differ experience a change in valuation, this will affect the counterfactual. The problem can be remedied by allowing the implicit price of the respective attribute to vary over time. We attempt to at least address the most obvious candidate, the gentrification of central neighborhoods, especially those with an attractive endowment of consumption amenities (Glaeser et al., 2001). We therefore interact the year dummies with the distance to the central business district and a kernel smoothed density surface of bars, pubs, nightclubs and hotels. We also add a full set of 23 city district $\times$ year

14 Traffic Cells (Verkehrszellen) are statistical areas originally used by the local administration to analyze traffic. There are 323 traffic cells in Berlin; the average size is 2.7 square kilometers (1.05 square miles). 
fixed effects to capture variation across district-year cells. We note that all the variables we interact with the year dummies are time-invariant to avoid problems of circular causation.

With the strong controls for time-invariant location features, the flexibility in time-varying implicit location attribute prices and a careful match between treated and non-treated properties discussed in section 3.3, we hope to establish a sufficiently well-defined counterfactual to benchmark the effect of the treatment over almost two decades. The two specifications of the treatment function we use produce treatment estimates that vary in the years $V$ since the designation of a renewal area occurred. For a given year since designation, the treatment estimate then reflects the cumulative effect of the improvement in the maintenance condition of a sold property $i$ on the price of $i$ and the external effect of the improvements in all other properties $j$ in the same neighborhood as $i$ on the price of $i$. Unlike in the theoretical example, the externality of buildings $j$ and $i$ is discounted by distance $D_{\mathrm{ij}}$ and may include the social externality of new residents moving into upgraded buildings:

$$
\beta_{V}=\frac{\partial P}{\partial I} \frac{\partial I_{i V}}{\partial S_{i V}}+\frac{\partial P}{\partial E} \sum_{j} \frac{\partial I_{j V}}{\partial S_{j V}} \tau\left(D_{i j}\right), \quad \text { where } \tau(D)>0 \text { and } \tau^{\prime}(D)<0
$$

\section{Treatment functions}

To capture the time-varying treatment effects $\beta_{V}$, we define two versions of $f\left(T_{i} \times V_{i t}\right)$. The first is a relatively restrictive parametric variant designed to allow for a level and a trend shift following designation:

$$
f\left(T_{i} \times V_{i t}\right)=\beta_{0} T_{i t} \times P O S T_{i t}+\beta_{1} T_{i t} \times V_{i t},
$$

where POST is an indicator variable taking the value of one if a property is sold after the respective renewal area has been designated. The year specific treatment effects are defined as $\beta_{V}=\beta_{0}+\beta_{1} V_{i t}$. The second approach follows Ahlfeldt \& Kavetsos (2013) and is more flexible. We group the treated observations into cohorts depending on $V_{i t}$. For each cohort, we then define an indicator variable $V D_{V i t}$ describing whether transactions fall into the cohort, e.g., $V D_{1 i t}=1$ for all observation transacted one year after designation of the respective renewal area. Interacting all cohort indicator variables with the treatment indica- 
tor $T$, we estimate a series of difference-in-difference treatment effects that compare how prices have changed since designation in the treatment and control groups:

$$
f\left(T_{i} \times V_{i t}\right)=\sum_{V} \beta_{v}\left(T_{i t} \times V D_{V i t}\right)
$$

The estimated $\hat{\beta}_{v}$ coefficients, hence, form a mix-adjusted hedonic price index that flexibly reflects the evolution of the treatment group relative to the control group. These two treatment functions have distinct strengths. The former allows for a straightforward assessment of whether the policy had a significant impact on levels or trends based on only two coefficients that can be estimated with relatively small standard errors. The latter approach produces a more flexible time-varying index but also larger confidence bands due to the relatively smaller number of observations per $V D_{V i t}$ cohort. In addition to employing these two distinct treatment functions, we vary the model along three more dimensions.

\section{Building quality}

In a first alternation, we only consider buildings in good condition to hold the quality of the traded buildings constant $\left(d I_{i}=\partial I_{i} / \partial S_{i}=0\right)$. Hence the estimated treatment effect collapses to $\beta=(\partial P / \partial E) \sum_{j} \partial I_{j} / \partial S_{j} \tau\left(D_{i j}\right)$. We choose to restrict the sample to properties in good condition (as opposed to poor condition), as it is less likely that these buildings are renovated shortly after the transaction. It is therefore also less likely that anticipated tax abatements or renovation subsidies are capitalized in the sales price. With this approach, we theoretically only capture the effects of improvements in the quality of buildings $j$ on the price of a sold building $i$ and, hence, a housing externality promoted by the policy. In practice, this approach to separating the internal and the external maintenance effect comes with some limitations. First, our data set offers two binary variables denoting whether a property, at the time of the transaction, was in a particularly good or poor condition. While this is significantly more information than available in most comparable data sets, this is also evidently far from perfect. Further, we have assumed that there are no policy effects on neighborhood quality other than through housing externalities. If there are significant direct investments in the quality of local public goods, e.g., the renovation of schools or playgrounds, these location features become a function of the policy. Adding these features $Q_{q}(S)$ to the original price equation results in an additional component in the treatment effect we measure: 


$$
\beta_{V}=\left(\frac{\partial P}{\partial I} \frac{\partial I_{i V}}{\partial S_{i V}}+\right) \frac{\partial P}{\partial E} \sum_{j} \frac{\partial I_{j V}}{\partial S_{j V}} \tau\left(D_{i j}\right)+\sum_{q} \frac{\partial P}{\partial Q_{q}} \frac{\partial Q_{j q}}{\partial S_{j q}}
$$

As such improvements in $Q_{q}(S)$ are difficult to observe, it is difficult to separate them from the housing externalities. We employ an alternative approach to measuring housing externalities focusing on spillovers into areas just outside renewal areas. This approach, which is described next, is closer to RH. It suffers, however, from a similar problem in that it is difficult to separate the housing externality spillover effect from an accessibility effect to improved local public goods in nearby areas. In practice, this interpretation problem is mitigated by the fact that both approaches consistently indicate that the joint neighborhood effect (housing externality and local public goods effect) was fairly limited. Irrespectively of this problem, a significant reduction in the treatment effect when holding building quality constant indicates the presence of a significant internal capitalization effect.

\section{Spillover effects}

One of the advantages of the approach above is that we aim at measuring policy induced housing externalities where they are presumably strongest, i.e., within renewal areas. One of the problems with this approach, as discussed, is that the information on building maintenance we use is imperfect. We therefore employ an alternative approach in which we focus on areas just outside the designated renewal areas. While attenuated, housing externalities should still be present in these areas. Moreover, any price effect will not be confounded with the policy effect on the internal quality of buildings because the respective areas did not qualify for subsidies. The treatment effect we estimate, hence, depends purely on the valuation of the housing externality and the policy effect on the maintenance level of buildings $j$ in a nearby renewal area, discounted by distance $D$ :

$$
\beta_{V}=\frac{\partial P}{\partial E} \sum_{j} \frac{\partial I_{j V}}{\partial S_{j V}} \tau\left(D_{i j}\right), \quad \text { where } \tau(D)>0 \text { and } \tau^{\prime}(D)<0
$$

This approach also mitigates another concern, namely, that authorities reserve the right to levy the increase in land value generated by the policy ("Ausgleichsabgabe"). Until the end of 2011, local authorities generated $€ 68$ mill. (\$93.3 mill.) in levies. The total expected levies estimated by the local administration amount to $€ 211$ mill. ( $\$ 285.3$ mill.) based on an estimated average increase in land value of $€ 45$ (\$60.8) per $\mathrm{m}^{2}$ (Senatsverwaltung Berlin (2012)), which are strikingly low figures compared to the above mentioned investment 
volumes. ${ }^{15}$ While these payments are in practice small, property prices could be negatively affected, at least up to the point where the levy has actually been charged.

To detect spillovers, we alter the definition of the treatment $T$ measure and the control groups relative to the benchmark specification (1). In the first alteration, we redefine our treatment measure as a binary variable that takes the value of $T_{S 1 i}=1$ if a property falls within a $500 \mathrm{~m}$ buffer area and zero otherwise. We run this specification using the two treatment functions introduced above and varying control groups. Focusing on the parametric specification and our preferred control group, we then use an alternative treatment measure $T_{S 2 i}=\beta_{S} T_{S 1 i}+\beta_{S 2} D I S T S_{i}$, where DISTS is the distance to the nearest renewal area.

\section{Sensitivity analysis and treatment heterogeneity}

The models discussed above produce an average effect of the treatment based on dozens of treatment and control areas. This setting has the advantage of being relatively insensitive to idiosyncratic factors that affect trends in individual renewal or control areas, but cancel out across areas. We complement the estimation of the average treatment effect using a sensitivity analysis in which we replicate our preferred model using randomly selected subsamples of treated and control areas. To provide individual estimates by renewal area we use a simplified long-difference approach, in which we compare changes in mean prices before and 15 years after designation (the average designation time) in the treatment and control group of properties near the treated area. We briefly discuss the results in the main paper and leave a detailed presentation of the model and the results to the technical appendix.

\subsection{Control Groups}

We define a number of control groups (CG) for the benchmark (renewal area) models (CG 1a-4a) and the spillover models (CG 1b-4b).

For all control groups, we exclude a $500 \mathrm{~m}$ buffer area around the renewal areas, to rule out a treatment effect on the control groups due to spillovers. CG 1a includes all observa-

15 All income generated through this source is to be reinvested in the district's infrastructure or neighborhood improvements. 
tions outside the urban renewal areas and the 500 m buffer. In CG 2a, we impose a geographical limit by considering transactions that lie within a 500 to 2,000 meter (approx. 6,000 ft.) distance from the renewal areas. CG 3a consists of the fractions of investigation areas outside the $500 \mathrm{~m}$ buffer that were not transformed into renewal areas - similar to RH. As a further alternative, CG 4 a is created based on the propensity score matching procedure proposed by Rosenbaum \& Rubin (1983). For the spillover models that use the 0$500 \mathrm{~m}$ buffer area around the renewal areas as a treatment group, CG1(b) and CG2(b) are defined exactly as before. CG 3b encompasses transactions in investigation areas outside the $500 \mathrm{~m}$ buffer, plus a 500 meter buffer around the investigation areas. For CG 4b, we again use the synthetic matching procedure to find suitable matches to the transactions in the buffer around the renewal areas.

For the synthetic matched control groups ( $4 \mathrm{a}$ and $4 \mathrm{~b}$ ), we match transactions inside and outside renewal areas (or buffer areas) based on the propensity score, a likelihood of being selected for the treatment based on observable characteristics. If transactions that are similar in observable characteristics are also similar in unobservable characteristics, the resulting control groups will produce a valid counterfactual for the treated. In the estimation of the propensity score, we choose covariates that influence both participation in the treatment and the outcome variable. To avoid anticipation effects, only locational variables that are measured before the treatment or are time invariant are considered (Caliendo \& Kopeinig, 2008). These covariates include a range of internal property and external location characteristics and are discussed in greater detail in the technical appendix, where we also present some descriptive statistics for the resulting samples.

\subsection{Data and descriptive statistics}

Our study area comprises the area of the Federal State of Berlin, Germany. The city in 2012 counted some 3.3 mill. inhabitants and approximately 1.9 mill. dwelling units. Approximately $14 \%$ of the population is non-German citizens. While there have recently been signs of economic recovery after a relatively long period of economic struggle since unification, the unemployment rate has remained relatively high at approximately $13 \%$. The overall area is approximately 892 square kilometers (344 square miles). The center is densely populated, the overall building structure is a mix of historic buildings (aged approximately 100-130 years), and buildings constructed after World War II to substitute for the destroyed building stock (aged approximately 60 years), and newer buildings. 
Within this study area, we observe all transactions of developed land that took place between January 1990 and August 2012, which amounts to approximately 70,000 transactions. The data set includes price, transaction date, location, and a set of parameters describing building / plot characteristics. The data are obtained from the Committee of Valuation Experts Berlin 2012 (Gutachterausschuss Berlin). The transactions are georeferenced (addresses and $\mathrm{x} / \mathrm{y}$ coordinates), which allows them to be integrated into a geographical information system (GIS) environment. The building characteristics include floor space, plot area, surface area, age ( $2^{\text {nd }}$ order polynomial), land use, location within a block of houses (e.g., a corner lot), among other variables. Additionally, we merge a set of location variables generated in GIS. These include the distance of the transactions to the nearest public transport station, school, public park, lake or river, the central business district, the nearest listed building, and the nearest main street and the street noise level. To control for time-varying implicit prices of proximity to consumption amenities, we generate a kernel smoothed density surface based on the 2012 location of bars, coffee shops, restaurants, nightclubs and hostels. We use a kernel radius of 2,000 meters and a quadratic kernel function (Silverman, 1986). The data are obtained from the open street map project, where users submit data to generate a publicly accessible street map. ${ }^{16}$ While these data are not official, but user-generated, they should provide a reasonable approximation of the actual distribution as long as the reporting probability does not vary systematically across space. The full list of considered variables is provided in Table A5 in the web based appendix.

From the Berlin Senate Department, we obtained maps showing the exact locations and boundaries of the 39 initial investigation areas as well as the fractions that were subsequently designated in three waves in 1993,1994, and 1995. Out of the originally proposed 39 investigation areas, 17 remained entirely unconsidered in the eventual selection. From the remaining 22 areas a total of $69 \%$ of the land area entered the program. The fragmentation of some of the 39 initial investigation areas results in 22 self-contained zones that were treated as well as another 22 zones that remained untreated. We have digitally processed the maps and converted them to a shape file to merge the information with the other spatial data in GIS. The 22 renewal areas have a mean size of approximately 0.37 square kilometers (median 0.35). The investigation areas have an average area of 0.43

16 www.openstreetmap.org 
square kilometers (median 0.36). As one would expect from the renewal and investigation areas having been chosen due to similar building, socio-demographic and geographic characteristics, the areas are also relatively similar in other observable characteristics. ${ }^{17}$

Figure 1 shows of the spatial distribution of the renewal / investigation areas along with our estimated smoothed kernel density surface and one of our synthetic control groups (CG 4a). From the figure, some notable stylized facts become evident. First, the majority of the renewal (17 out of 22) and investigation areas (31 of 39) are located in the former East Berlin, which is not surprising given that the eastern part of the city suffered even more severely during the period of division. Second, renewal areas and revitalization areas are typically located in central areas and in amenity clusters and, hence, areas that are typical candidates for gentrification. It is important to fully acknowledge this spatial pattern, as a failure to select sufficiently similar control groups or account for a change in appreciation of these characteristics may result in a policy treatment effect that could be confounded with a general gentrification phenomenon. Third, our synthetic control groups (red dots) consist of transactions that are either close to renewal or investigation areas or in areas of high amenity densities, which lends some confidence to the selection process.

17 Table A1 in the web based appendix lists the renewal areas and some stylized facts per area, while Table A2 compares key characteristics across the renewal areas, the investigation areas, and the rest of Berlin. 
Fig. 1: Renewal geography

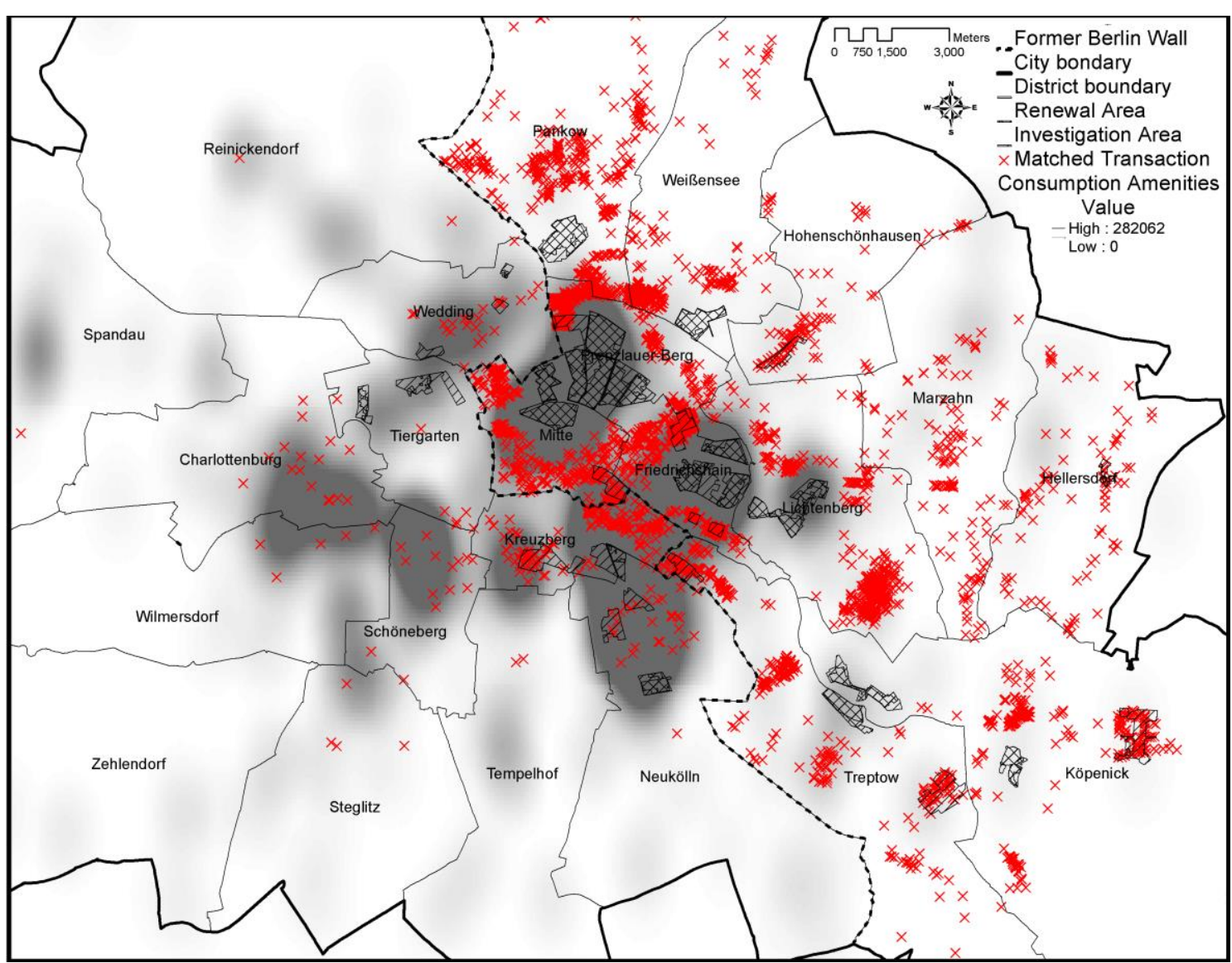

Notes: Notes: Own illustration based on the urban and environmental information system (Senatsverwaltung für Stadtentwicklung Berlin, 2006). Crosshatched (hatched) areas indicate renewal (investigation) areas. Red crosses are the matched transactions in CG 4a. Smoothly grey shaded areas represent the consumption amenity density.

As discussed above, the information on maintenance condition it is a special feature of our property data set. The variables are coded by specialist teams of the Committee of Valuation Experts Berlin, who undertake on-site examinations for each transaction of developed land that takes place. In Figure 2, we plot how the conditional mean shares of transacted properties in either good or poor condition evolved in the renewal areas relative to the revitalization areas over time. The indices are generated using auxiliary regressions described in the figure notes. From the mix-adjusted quality trends, it is evident that the quality of the housing stock in the renewal areas improved significantly over time. In 1990, the fraction of buildings in poor condition in renewal areas was significantly larger than in the investigation areas, possibly a reason for their selection. The difference steadily declines over time. By the end of the observation period, the relationship is at the margin of becoming negative and statistically significant. While the conditional mean shares of properties in good maintenance were virtually the same in 1990, the proportion was sig- 
nificantly larger in the renewal areas by the end of the period. Figure 2 demonstrates this development and indicates that the renewal program accelerated the upgrading of the housing stock that was left behind during the division period.

Fig. 2: Maintenance trends in renewal areas

\section{Condition Good}

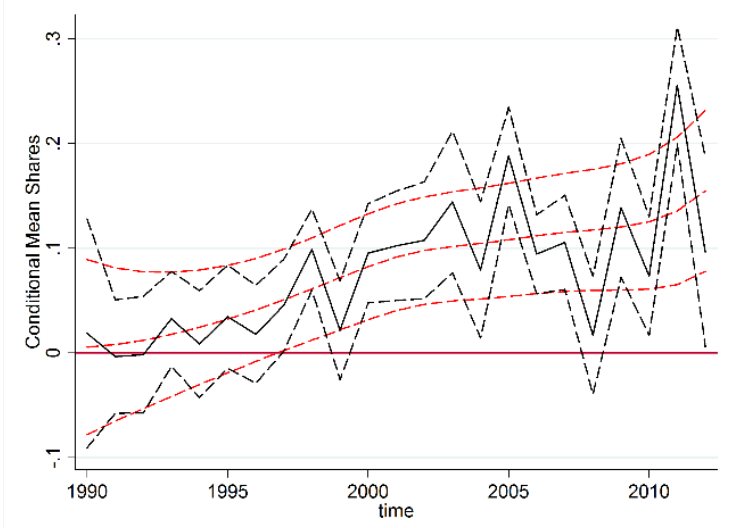

Condition Bad

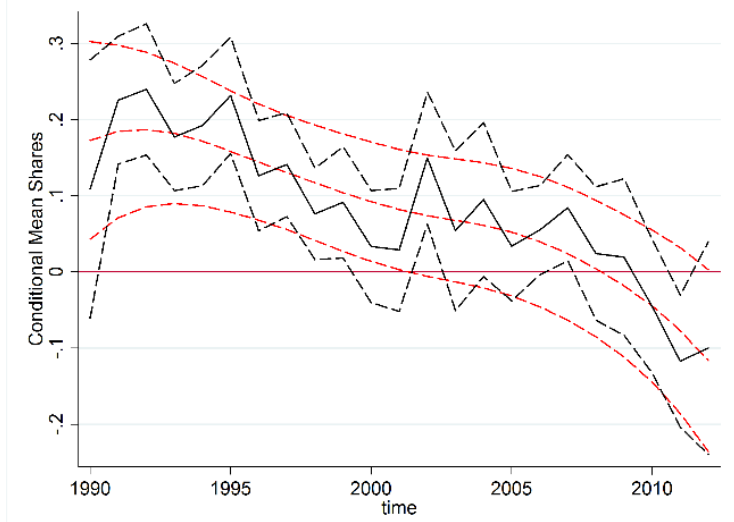

Notes: Year specific differences in mean shares are estimated in two separate regressions of the following type: $Y_{i t}=\sum_{t} \beth_{t} T_{i} \times \varphi_{t}+\sum_{o} X_{o t}+\varphi_{t}+\epsilon_{i t}$, where $Y_{i t}$ indicates whether a property at time $t$ was in good (left) or poor (right) maintenance and $X_{0}$ controls for the following property features: age, plot area, and floor space index. $T_{i}$ is an indicator variable discriminating between whether a property falls within a renewal area $(\mathrm{T}=1)$ or within a revitalization area $(\mathrm{T}=0)$. Black solid (dashed) lines indicate $\beth_{t}$ point estimates (95\% confidence intervals). Red dashed lines are lowess smoothes of the parameters. Similar trends with alternative sets of covariates are presented in Figure A2 in the appendix.

Controlling for additional property features does not generally significantly alter the results, nor does using the other control groups. Alternative estimations using additional covariates and different control groups are presented and discussed in the appendix.

\section{Empirical Results}

\section{Renewal area effects}

Table 1 summarizes our parametric estimates (see specification 11) of renewal area capitalization effects by varying control groups and samples. For the sake of brevity, we focus on the treatment estimates of primary interest. The complete estimates of the structural and location parameters are in line with the typical findings in similar studies and reported in Table A6 in the web based appendix. The parameter on TxPOST $\left(\beta_{0}\right)$ indicates a shift in $\log$ prices at the time of designation, while the parameter on $\operatorname{Tx} V\left(\beta_{1}\right)$ reveals the yearly percentage appreciation within the renewal areas relative to the control areas in the post 
designation period. Based on the two estimated parameters, the aggregated renewal policy effect for any given year since designation can be computed as $\left(\exp \left(\beta_{0}+\beta_{1} V_{i t}\right)\right)^{18}$

Models (1-6) (upper panel of Table 1) estimate the gross-capitalization effect of the policy comprising both internal property and externality effects. Model 1 compares the evolution of property prices within the renewal areas to the rest of Berlin, our most general control group (1a). The results suggest that a positive long-run trend (approximately $4.7 \%$ per year) dominates a negative intercept (-16.2\%). After $V=20$ years, sales prices in designated renewal areas, on average, have appreciated by as much as $119.4 \%$ relative to the rest of the city. This corresponds to an average yearly appreciation rate of approximately $(1+119.4 \%)^{1 / 20}-1=4.01 \%$. As we increase the strength of the counterfactual using spatially proximate properties (2), the investigation areas (3) or the matched properties (4) as a control group, the cumulative effect (average appreciation rate) drops to $94.49 \%$ (3.3\%), 49.79\% (2.04\%), and 42.7\% (1.79\%), respectively. Most notable are the effects of the inclusion of time-varying effects in models (5) and (6), which compared to the baseline models (3) and (4), reduce the cumulative effect to - a non-significant - 7.33\% (8.3\%) in model 5 (6). This implies a - non-significant - average annual appreciation of approximately $0.375 \%$. One interpretation of this remarkable decline is that the relative appreciation of the renewal areas is to a significant extent driven by their favorable location with respect to distance to the $\mathrm{CBD}$, consumption amenity endowment and the districts they fall in, i.e., they would have appreciated even in the absence of the policy. If, however, the changes in the implicit prices (e.g., of distance to the CBD) were driven by the policy, e.g., central locations became generally more attractive because of the renewal efforts, the time-varying effects would be absorbing some variation that was genuinely attributable to the policy. ${ }^{19}$ To this extent, the results in columns (5) and (6) represent lower bound estimates of the policy impact and those in columns (3) and (5) indicate upper bounds.

The estimated effects tend to decline relative to the comparable full models when the sample is restricted to properties in good physical condition (lower panel of Table 1). Moreover, the results are relatively unstable across varying control groups, and none of

18 We make use of the conventional interpretation of dummy variables in semi-log models (Halvorsen \& Palmquist, 1980).

19 This problem is a variant of the "bad control problem" (Angrist \& Pischke, 2009). 
the effects are estimated at satisfying levels of statistical significance. While this may be partially driven by the reduction in observations and loss of degrees of freedom (which also leads us to not estimate the demanding model with time varying effects on this sample), the results are at least indicative that the benchmark results are not primarily driven by externality effects.

Tab. 1. Renewal Area Treatment Effects

\begin{tabular}{|c|c|c|c|c|c|c|}
\hline \multirow[t]{4}{*}{ Control group } & $1 a$ & $2 a$ & $3 a$ & $4 a$ & $3 a$ & $4 a$ \\
\hline & All & All $<2 \mathrm{~km}$ & $\begin{array}{l}\text { Investiga- } \\
\text { tion Areas }\end{array}$ & $\begin{array}{c}\text { Matched } \\
\text { Observa- } \\
\text { tions }\end{array}$ & $\begin{array}{c}\text { Investigation } \\
\text { Areas }\end{array}$ & $\begin{array}{c}\text { Matched } \\
\text { Observa- } \\
\text { tions }\end{array}$ \\
\hline & \multicolumn{6}{|c|}{ All properties } \\
\hline & (1) & (2) & (3) & (4) & (5) & $(6)$ \\
\hline$T \times P O S T$ & $-0.162 * * *$ & $-0.115 * * *$ & -0.060 & $-0.139 * * *$ & $-0.120 * * *$ & -0.026 \\
\hline (within renewal) & $(0.036)$ & $(0.037)$ & $(0.039)$ & $(0.052)$ & $(0.045)$ & $(0.061)$ \\
\hline$T \times V$ (years since & $0.047 * * *$ & $0.039 * * *$ & $0.023 * * *$ & $0.025 * * *$ & $0.010 * * *$ & 0.005 \\
\hline designation) & $(0.003)$ & $(0.004)$ & $(0.004)$ & $(0.004)$ & $(0.004)$ & $(0.005)$ \\
\hline Cum. effect after & $119.4 \% * * *$ & $94.49 \% * * *$ & $49.79 \% * * *$ & $42.7 \% * * *$ & $7.33 \%$ & $8.3 \%$ \\
\hline 20 years & (6.62\%) & $(6.84 \%)$ & $(7.32 \%)$ & (9.79\%) & $(7.32 \%)$ & $(11.12 \%)$ \\
\hline Av. appr. Rate & $4.01 \%$ & $3.38 \%$ & $2.04 \%$ & $1.79 \%$ & $0.35 \%$ & $0.4 \%$ \\
\hline Observations & 64,677 & 17,447 & 8,623 & 8,860 & 8,623 & 8,860 \\
\hline $\mathrm{R}^{2}$ & 0.802 & 0.772 & 0.632 & 0.710 & 0.677 & 0.735 \\
\hline AIC & $79,932.8$ & $25,276.8$ & $12,347.3$ & $13,477.5$ & $11,778.3$ & $13,226.6$ \\
\hline Hedonic Controls & YES & YES & YES & YES & YES & YES \\
\hline Location controls & YES & YES & YES & YES & YES & YES \\
\hline Traffic Cell E. & YES & YES & YES & YES & YES & YES \\
\hline Year Effects & YES & YES & YES & YES & YES & YES \\
\hline \multirow[t]{3}{*}{ Time-Varying E. } & NO & NO & NO & NO & YES & YES \\
\hline & \multicolumn{6}{|c|}{ Buildings in good condition } \\
\hline & $(7)$ & (8) & (9) & $(10)$ & & \\
\hline$T \times P O S T$ & 0.008 & -0.070 & 0.084 & 0.500 & - & - \\
\hline (within renewal) & $(0.338)$ & $(0.416)$ & $(1.063)$ & $(1.232)$ & & \\
\hline$T \times V$ (years since & -0.000 & -0.002 & -0.026 & -0.001 & - & - \\
\hline designation) & $(0.012)$ & $(0.014)$ & $(0.019)$ & $(0.019)$ & & \\
\hline Cum. effect after & $0.67 \%$ & $-9.84 \%$ & $-35.94 \%$ & $62.55 \%$ & - & - \\
\hline 20 years & $(39.49 \%)$ & $(50.23 \%)$ & $(187.56 \%)$ & $(245.52 \%)$ & & \\
\hline Av. appr. Rate & $0.003 \%$ & $-0.52 \%$ & $-2.2 \%$ & $2.4 \%$ & - & - \\
\hline Observations & 15,406 & 2,567 & 787 & 948 & - & - \\
\hline $\mathrm{R}^{2}$ & 0.917 & 0.941 & 0.863 & 0.890 & - & - \\
\hline AIC & $5,491.0$ & $1,475.9$ & 558.9 & 738.4 & - & - \\
\hline Hedonic Controls & YES & YES & YES & YES & & \\
\hline Location Controls & YES & YES & YES & YES & & \\
\hline Traffic Cell E. & YES & YES & YES & YES & & \\
\hline Year Effects & YES & YES & YES & YES & & \\
\hline Time-Varying E. & NO & NO & NO & NO & & \\
\hline
\end{tabular}

Notes: Standard errors in parentheses. ${ }^{*} \mathrm{p}<0.1{ }^{* *} \mathrm{p}<0.05,{ }^{* * *} \mathrm{p}<0.01$. Hedonic and location controls consist of covariates controlling for internal property and external location characteristics described in greater detail in the data section and the appendix. Time-varying controls are sets of interaction effects of year effects and distance to the CBD, district effects and a consumption amenity measure described in the data section. 
Figure 3 illustrates our semi-non-parametric estimates of the temporal treatment function according to equation 12. We present estimates for all properties (upper row), all properties including time varying effects (middle row), and properties in good condition only (bottom row) using control group 1a (all properties outside renewal areas) and 3a (properties in investigation areas). The semi-non-parametric estimates are generally in line with the parametric counterparts presented in Table 1. The cumulative effect on all properties inside renewal areas relative to those outside the renewal areas is even slightly larger than implied by the parametric estimates (upper left), but declines to approximately $50 \%$ when the trend is benchmarked against the investigation areas (upper right). The positive trend effects seem to capitalize with some delay (beginning after approximately 5 years). The negative level shifts found in Table 1, thus, appear to be primarily driven by parametric constraints and should not necessarily be taken as indicative of a significant decline in prices immediately following designation. We note that the cumulative effect after 20 years in the models with time-varying effects is within the same range as model (5) in Table 1 but not statistically significant. Focusing on properties in good condition, we again find that the cumulative effect after 20 years is not statistically distinguishable from zero, partly due to large standard errors. We are, thus, not able to affirm the existence of significant revitalization effects based on the most demanding semi-parametric models. 
Fig. 3: Price trends in renewal areas, relative to varying control groups

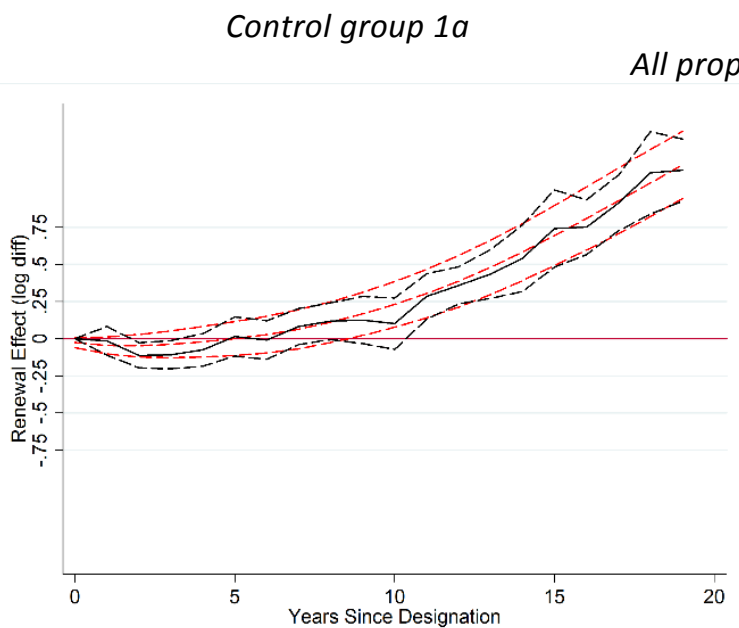

Control group $3 a$

All properties

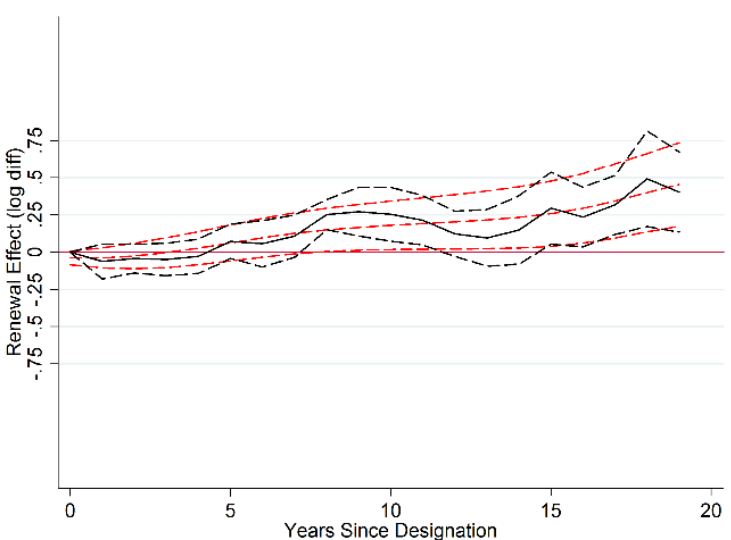

All properties \& time varying effects

Control group $1 a$

Control group $3 a$
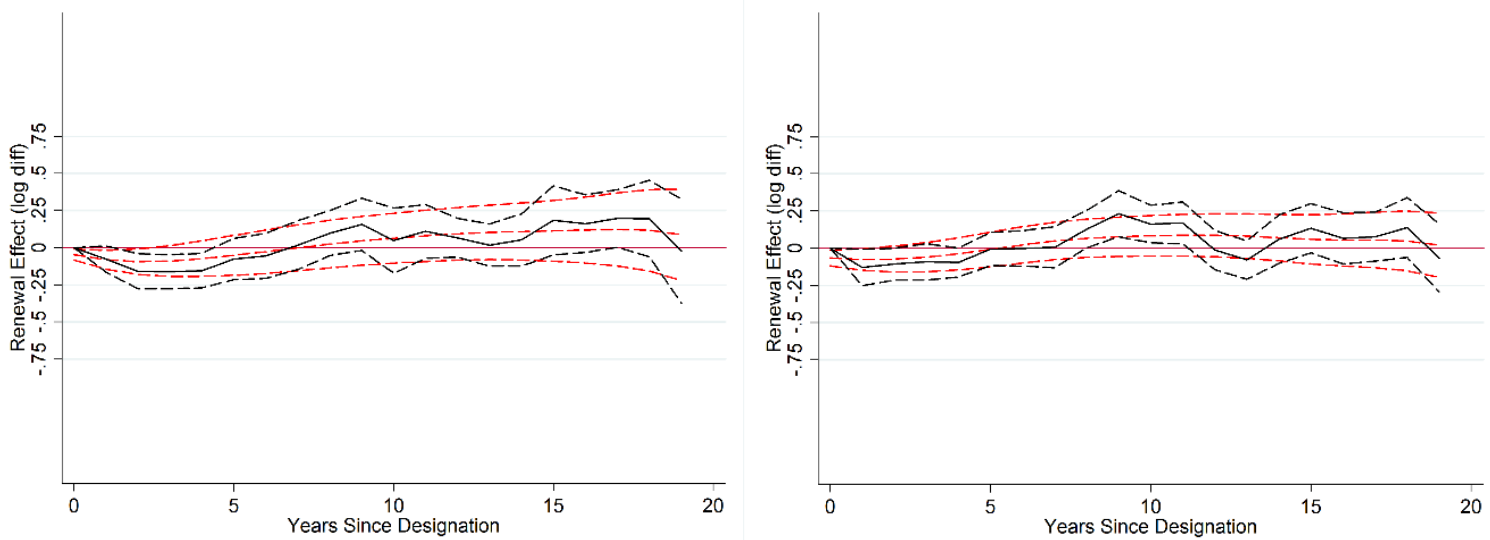

In good condition

Control group $1 a$

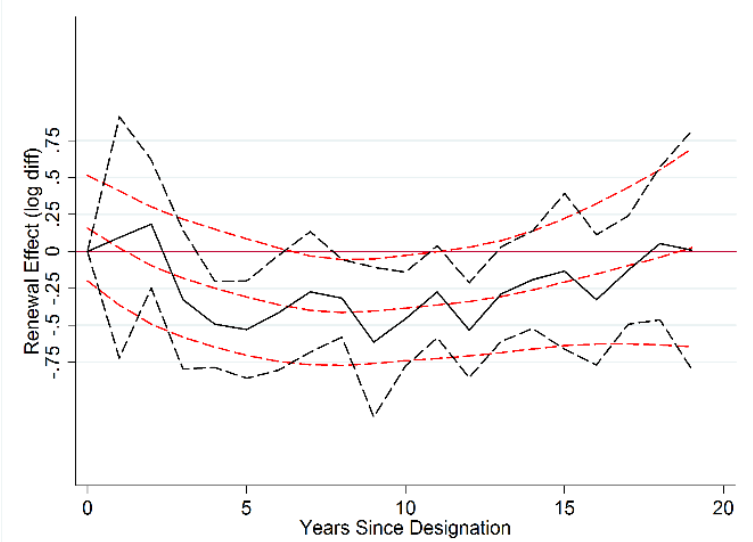

Control group $3 a$

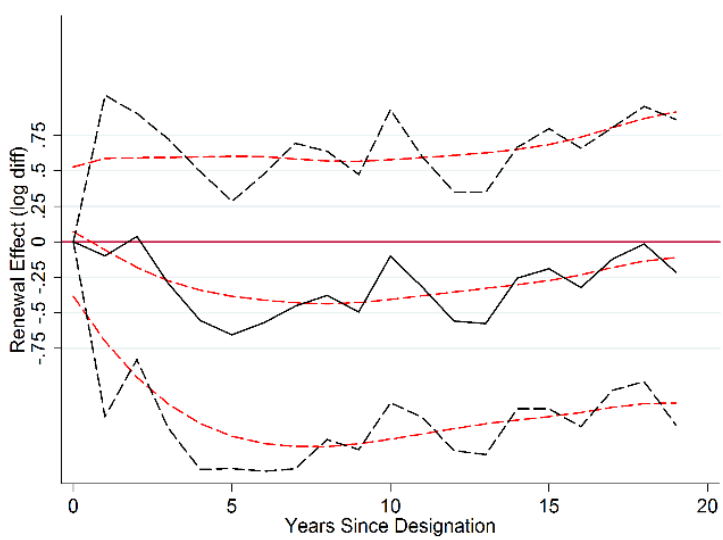

Notes: Black solid (dashed) lines indicate treatment point estimates ( $95 \%$ confidence intervals). Red dashed lines are lowess smoothes of the parameters. 


\section{Spillover effects}

Table 2 and Figure 4 replicate the analysis for the spillover areas, i.e., the $500 \mathrm{~m}$ buffer just outside the renewal areas. As the external areas have not been targeted by the policy, housing externalities can be identified using all buildings irrespective of their maintenance condition. The $500 \mathrm{~m}$ buffer area previously excluded due to the presence of spillovers now serves as a treatment group to detect spillover effects. Lower thresholds generally yield similar results, but suffer from a loss of degrees of freedom. The results are easily summarized. For our preferred control groups ( 3 and 4), we find results that are within the same range as the internal effects in the baseline model (columns 3 and 4). The revitalization effect, however, is statistically indistinguishable from zero once we control for independent appreciation trends that using the time-varying effect.

Tab. 2. Renewal Area Spillover Effects

\begin{tabular}{|c|c|c|c|c|c|c|}
\hline \multirow[t]{4}{*}{ Control group } & $1 \mathrm{~b}$ & $2 b$ & $3 b$ & $4 b$ & $3 b$ & $3 b$ \\
\hline & All & $\begin{array}{c}<2 \mathrm{~km} \\
\text { renewal } \\
\text { area buffer }\end{array}$ & $\begin{array}{c}\text { Invest. } \\
\text { Areas + } 1 \\
\text { km } \\
\text { buffer }\end{array}$ & $\begin{array}{c}\text { Matched } \\
\text { Observations }\end{array}$ & $\begin{array}{c}\text { Invest. } \\
\text { Areas + } 1 \\
\text { km buffer }\end{array}$ & $\begin{array}{c}\text { Matched } \\
\text { Observations }\end{array}$ \\
\hline & \multicolumn{6}{|c|}{500 meter buffer } \\
\hline & (1) & $(2)$ & (3) & (4) & (5) & (6) \\
\hline $\begin{array}{l}T \times P O S T \\
\text { (within renewal) }\end{array}$ & $\begin{array}{c}-0.124^{* *} \\
(0.052)\end{array}$ & $\begin{array}{c}-0.145 * * \\
(0.059)\end{array}$ & $\begin{array}{c}-0.149 * * \\
(0.061)\end{array}$ & $\begin{array}{l}-0.095^{*} \\
(0.056)\end{array}$ & $\begin{array}{l}-0.052 \\
(0.056)\end{array}$ & $\begin{array}{l}-0.057 \\
(0.067)\end{array}$ \\
\hline $\begin{array}{l}T \times V \text { (years } \\
\text { since designation) }\end{array}$ & $\begin{array}{c}0.020^{* * *} \\
(0.004)\end{array}$ & $\begin{array}{c}0.023 * * * \\
(0.004) \\
\end{array}$ & $\begin{array}{c}0.025^{* * *} \\
(0.004)\end{array}$ & $\begin{array}{c}0.024 * * * \\
(0.004)\end{array}$ & $\begin{array}{l}-0.000 \\
(0.004)\end{array}$ & $\begin{array}{c}0.000 \\
(0.004)\end{array}$ \\
\hline Cum. effect after & $31.6 \% * * *$ & $38.25 \% * * *$ & $42.9 \% * * *$ & $46.46 \% * * *$ & $-4.41 \%$ & $-4.67 \%$ \\
\hline 20 years & $(6.06 \%)$ & $(6.54 \%)$ & $(6.68 \%)$ & $(7.06 \%)$ & $(5.63 \%)$ & $(8.41 \%)$ \\
\hline Av. appr. Rate & $1.38 \%$ & $1.63 \%$ & $1.8 \%$ & $1.93 \%$ & $-0.23 \%$ & $-0.24 \%$ \\
\hline Observations & 66,865 & 19,421 & 11,963 & 16,989 & 11,963 & 16,989 \\
\hline $\mathrm{R}^{2}$ & 0.690 & 0.657 & 0.605 & 0.636 & 0.671 & 0.662 \\
\hline AIC & $113,544.3$ & $36,076.0$ & $21,172.5$ & $32,244.7$ & $19,093.6$ & $30,244.1$ \\
\hline Hedonic Controls & YES & YES & YES & YES & YES & YES \\
\hline Location controls & YES & YES & YES & YES & YES & YES \\
\hline Traffic Cell E. & YES & YES & YES & YES & YES & YES \\
\hline Year Effects & YES & YES & YES & YES & YES & YES \\
\hline Time-Varying E. & NO & NO & NO & NO & YES & YES \\
\hline
\end{tabular}

Notes: Marginal effects; standard errors in parentheses. ${ }^{*} \mathrm{p}<0.1,{ }^{* *} \mathrm{p}<0.05,{ }^{* * *} \mathrm{p}<0.01$. Hedonic and location controls consist of covariates controlling for internal property and external location characteristics described in greater detail in the data section and the appendix. Time-varying controls are sets of interaction effects of year effects and distance to the CBD, district effects and a consumption amenity measure described in the data section. 
Fig. 4: Price trends in spillover areas, compared to different control groups

Control group $1 b$

Control group $3 b$
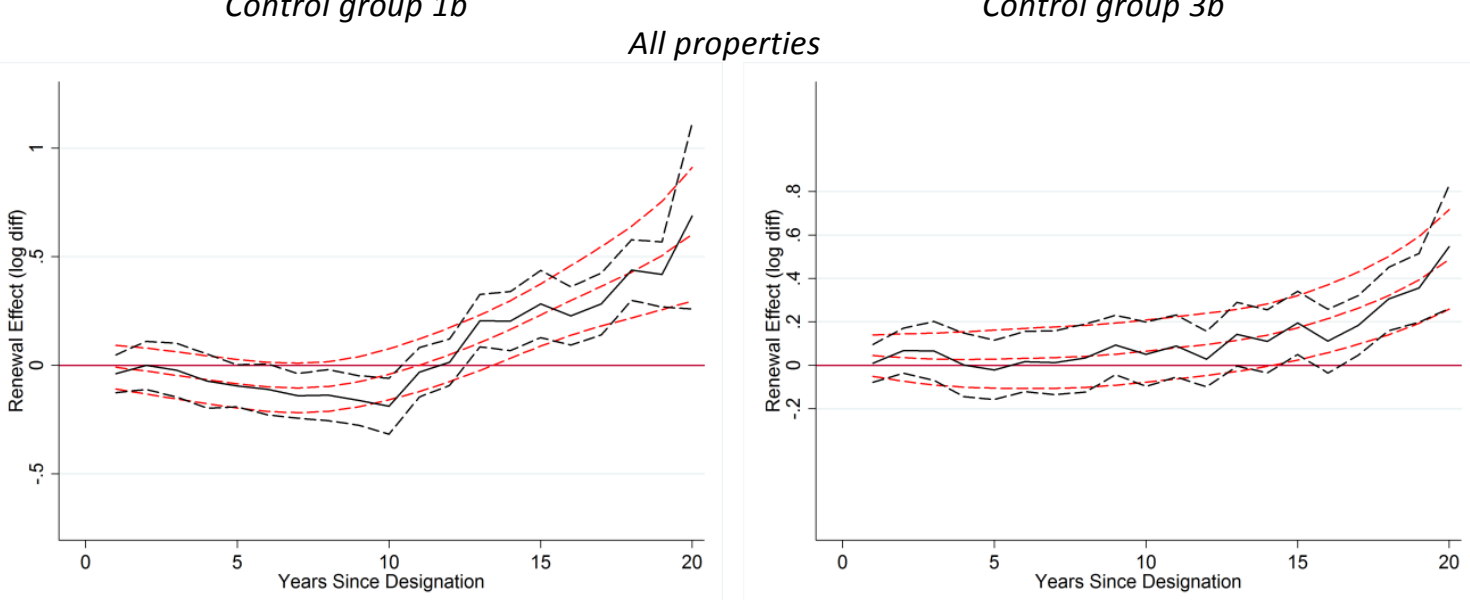

Control group $1 b$

All properties \& time varying effects
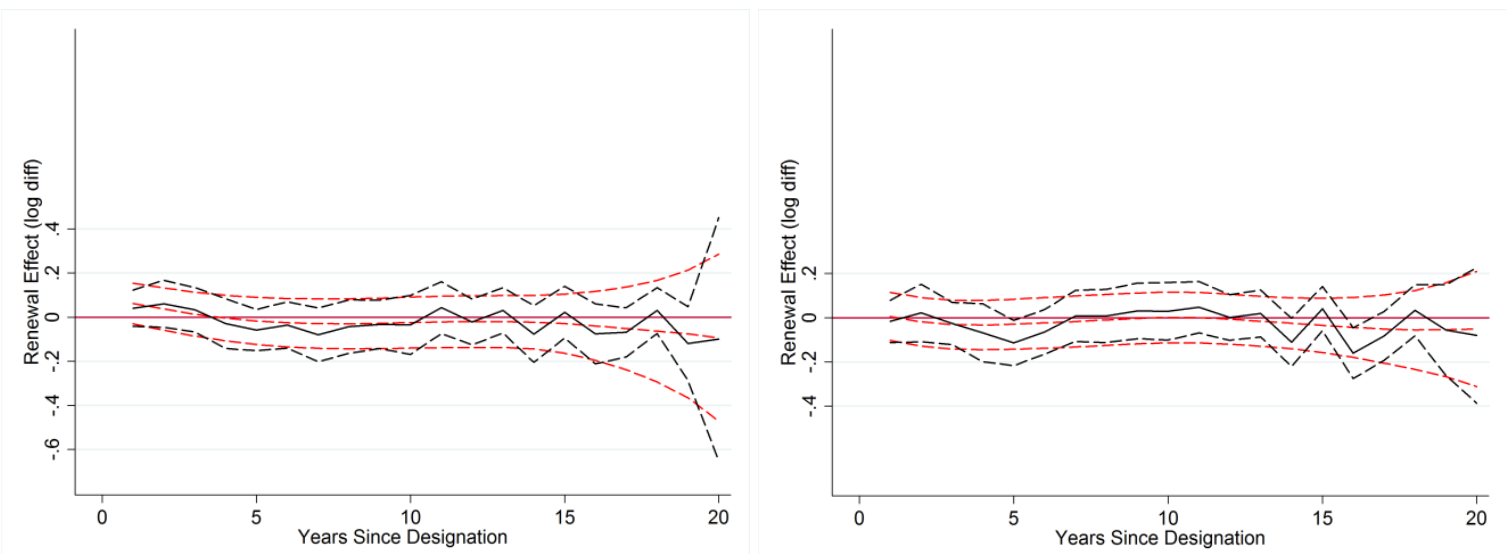

Notes: Black solid (dashed) lines indicate treatment point estimates (95\% confidence intervals). Red dashed lines are lowess smoothes of the parameters.

\section{Robustness and extension}

A number of alterations to the renewal and spillover models are discussed in more detail in the appendix. We test for the possibility that the designation of renewal areas represented a negative signal to the remaining investigation areas, which could invalidate the counterfactual provided. We replace the contemporary amenity density with an analogically constructed variant that uses bars and restaurants as reported in the 1995/6 edition of the yellow pages (Gelbe Seiten), which should predate the impact of the designation of renewal areas. To estimate the spillover effect holding the quality of the building stock constant, we add maintenance controls to the spillover models. We use distance to the renewal area boundary as a (external) treatment measure to account for the possibility 
that a housing externality is steeply decaying within the spillover area. To allow for contagion in the spillover effect, we further model an interaction of the spatial decay with the time trend. All results support the interpretations and conclusions presented in this document.

\section{Sensitivity analysis and treatment heterogeneity}

One favorable feature of our empirical setting is the availability of a relatively large number of treatment ( 22 designated renewal areas) and control areas (22 self-contained zones out of 39 areas initially considered). Our empirical models control for unobserved timeinvariant spatial heterogeneity, unobserved shocks at the city district level and unobserved shocks that are correlated with distance to the CBD and the spatial distribution of consumption amenities. Successful identification rests on the assumption that the treated and control areas are subject to the same macro-economic shocks conditional on these controls. The relatively large number of treatment and control areas arguably helps with the identification because idiosyncratic year-area specific shocks are more likely to cancel each other out within larger groups of treated or control areas.

To evaluate the sensitivity of the identified treatment effect to the number of treated or control areas considered, we replicate our benchmark model using various combinations of $1,2,5,10,15,20$, or all treatment or control areas. For each combination considered, we run 2,500 iterations with randomly selected areas (unless the total number of combinations is exhausted at a lower number, in which case we simply run all combinations). The results are summarized in Table 3. One notable finding is that in all series, the mean of the estimated cumulated policy effects after 20 years is within approximately one standard deviation of zero, which is consistent with the policy not having a statistically significant impact. Equally important, the estimates tend to fall into a narrower range as the number of areas considered is increased. The percentage of individual estimates falling within two standard error lengths of our benchmark result (Table 1, column 5, upper panel) increase from 36 (32) to near 100 percent as we increase the number of treatment (control) areas from 1 to 15, holding the number of control (treated) areas constant. The effect is even larger if the number of treatment and control areas considered is increased at the same time. The estimates become reasonably precise once ten treated and control areas are selected. Selected distributions of the estimated effects are graphically illustrated in the appendix. 
We conclude that some care is warranted when interpreting the results of quasiexperimental place-based policy evaluations based on small numbers of treatment or control areas. While in practice, little can be done to overcome the limitation of a policy experiment that offers only a small number of targeted areas, the matching approach used in the construction of control groups $4 \mathrm{a} / \mathrm{b}$ can be considered as an alternative or a robustness check when only a few obvious candidate areas exist to establish a counterfactual.

Tab. 3. Varying groups of treated and controls

\begin{tabular}{|c|c|c|c|c|c|c|c|}
\hline \multicolumn{2}{|c|}{ No of areas } & \multicolumn{5}{|c|}{ Cumulated effect after 20 years } & \multirow{2}{*}{$\begin{array}{l}\% \text { within } 2 \text { S.E. length } \\
\text { of bench. }\end{array}$} \\
\hline Treat. & Control & Iterations & Mean & S.D. & Min & Max & \\
\hline \multicolumn{8}{|c|}{ Varying number of treated areas } \\
\hline 1 & 22 & 22 & 0.04 & 0.48 & -1.00 & 0.98 & $36.36 \%$ \\
\hline 2 & 22 & 462 & 0.02 & 0.30 & -0.91 & 0.64 & $52.81 \%$ \\
\hline 5 & 22 & 2500 & 0.05 & 0.18 & -0.62 & 0.53 & $80.00 \%$ \\
\hline 10 & 22 & 2500 & 0.07 & 0.11 & -0.30 & 0.42 & $96.44 \%$ \\
\hline 15 & 22 & 2500 & 0.08 & 0.08 & -0.16 & 0.30 & $99.80 \%$ \\
\hline 20 & 22 & 2500 & 0.09 & 0.08 & -0.18 & 0.30 & $99.64 \%$ \\
\hline \multicolumn{8}{|c|}{ Varying number of control areas } \\
\hline 22 & 1 & 22 & -0.12 & 0.34 & -0.67 & 0.69 & $31.82 \%$ \\
\hline 22 & 2 & 462 & -0.07 & 0.30 & -0.78 & 0.69 & $53.68 \%$ \\
\hline 22 & 5 & 2500 & -0.01 & 0.17 & -0.79 & 0.74 & $76.56 \%$ \\
\hline 22 & 10 & 2500 & 0.01 & 0.09 & -0.38 & 0.31 & $92.44 \%$ \\
\hline 22 & 15 & 2500 & 0.02 & 0.05 & -0.16 & 0.17 & $99.08 \%$ \\
\hline 22 & 20 & 2500 & 0.02 & 0.05 & -0.22 & 0.18 & $99.32 \%$ \\
\hline \multicolumn{8}{|c|}{ Varying number of treated and control areas } \\
\hline 1 & 1 & 2261 & 44.3 & 449 & -1242 & 10063 & $0.97 \%$ \\
\hline 2 & 2 & 2500 & 7.14 & 131 & -1054 & 3407 & $8.72 \%$ \\
\hline 5 & 5 & 2500 & 0.40 & 3.61 & -22.56 & 85.65 & $42.56 \%$ \\
\hline 10 & 10 & 2500 & 0.10 & 0.16 & -0.58 & 0.72 & $84.48 \%$ \\
\hline 15 & 15 & 2500 & 0.06 & 0.08 & -0.39 & 0.38 & $98.08 \%$ \\
\hline 20 & 20 & 2500 & 0.07 & 0.08 & -0.31 & 0.36 & $98.48 \%$ \\
\hline
\end{tabular}

Notes: Each row describes the distribution of the cumulated effects after 20 years derived from a series of estimations of the benchmark specification (equations $9+11$ ). The effects are expressed in units of log-differences. We consider all possible combinations of one or two treated vs. all (22) control areas and vice versa. For all other combinations we use 2500 randomly drawn selections.

The sensitivity analysis presented here has been deliberately established to illustrate the sensitivity of the baseline setup to varying numbers of treated and control areas. In the appendix, we provide treatment estimates by renewal area using a simplified version of the benchmark specification, which economizes on degrees of freedom at the expense of limiting causal inference. The results confirm a significant degree of treatment heterogeneity, suggesting that some areas may be more responsive to external stimuli than others.

\section{Conclusion}

Urban renewal programs have become a common instrument to mitigate and reverse the negative effects of urban decline and promote positive housing externalities. Public ex- 
penditures on such programs are justified on the grounds of the positive, non-marketed externality building maintenance is anticipated to have on economic (and social) outcomes and the hope that the (temporary) stimulation of private investment can trigger an upward spiral in a neighborhood.

We contribute to a fresh strand of literature that examines the economic outcomes of urban renewal policies recently inaugurated by $\mathrm{RH}$. We add to their case by analyzing a $\$ 2.3$ bill. neighborhood renewal program designed to promote the recovery of 22 neighborhoods in Berlin, Germany that had suffered particularly severely during the period of division in the $20^{\text {th }}$ century. We track the evolution of property prices in these neighborhoods over approximately 20 years and compare the trends to neighborhoods that were not selected for the program, but are otherwise similar.

Given the expectations that have motivated the renewal program in question and similar programs, our results are simultaneously encouraging and disillusioning. On the one hand, our results indicate that the policy led to increased renovation work, improved maintenance, and an appreciation of the renovated buildings in the targeted neighborhoods. Over approximately 20 years, the share of buildings in poor (good) condition declined (increased) by approximately $25 \%(10 \%)$ relative to similar untargeted areas. Compared to similar areas considered, but not selected for the program, property prices, on average, after 20 year of operation of the program increased by approximately $45 \%$, which equates to a yearly appreciation rate of $1.9 \%$. The appreciation is even larger compared to the city average.

Our results, however, also suggest that this appreciation is at least partially attributable to the favorable locations of these areas. Controlling for trends related to proximity to the CBD, the distribution of consumption amenities, and individual city districts, our most careful results point to a cumulative effect of less than $10 \%$, which corresponds to an annual appreciation of less than $0.5 \%$. Equally important, our results, on average, do not point to the self-reinforcing effect operating through housing externalities for which one may have hoped. The increase in property value seems largely attributable to the upgrade of internal quality, and there are no significant spillovers to adjacent areas. Back of the envelope calculations suggest that total property value increased by only $€ 0.35-€ 1.8$ for each $€ 1$ spent on the program, taking the abovementioned lower and upper bound estimates as a benchmark (see the appendix for details). We conclude that the policy sped up 
the renovation of significant fractions of the urban fabric and, as such, helped eliminating the visible traces of the division period. However, it has also primarily been a cash transfer to landlords participating in the program.

Despite the improvements in building stock likely caused by the policy, our results look less favorable than those previously presented by RH for the Neighborhoods in Bloom program in Richmond, Virginia. Analyzing a much smaller program of \$14 mill., RH find positive and large effects on property values in four renewal areas that exceed the investments by a factor of two to six and significant spillovers into adjacent areas. There are some explanations that may account for the large discrepancy in the findings for Richmond and Berlin. The first are the different structures of the two local communities. The Richmond program was more based on community volunteering and local non-profit organizations, while Berlin adopted a top-down approach implemented by official state authorities with little community participation. Second, and perhaps more important, German cities, and especially in Berlin, are not directly comparable to the average US city in that many residents choose to rent apartments. As a result, much of the downtown housing stock is owned by landlords and occupied by renters. Absentee landlords, however, are often argued to spend less on maintenance than owner-occupiers (Galster, 1983). Similarly, owners have been demonstrated to invest more in social capital (DiPasquale \& Glaeser, 1999; Hilber, 2010) and tend to use neighborhood policies as a framework to coordinate their behavior to internalize externalities (Holman \& Ahlfeldt, 2013), as such, they may also be more receptive to renovation subsidies. Third, there is some indication that the impact of the policy varied across targeted neighborhoods in Berlin. While the individual effects by renewal area need to be interpreted with care, the heterogeneity may indicate that some areas are more responsive to external stimuli than others.

Future research into the long-run effects of renewal policies across different institutional settings is needed to fully reconcile the evidence. Understanding the factors that determine how incentivizing private investment in building maintenance can lead to positive spillovers is key to deciding where such programs should be implemented and where the focus should be on improvements of fundamental location factors in the first place. More generally, we recommend that quasi-experimental place based policy evaluations be based on a sufficiently diversified set of treatment and control areas 


\section{Literature}

Ahlfeldt, G. M. (2011). Blessing or Curse? Appreciation, amenities and resistance to urban renewal. Regional Science and Urban Economics, 41(1), 32-45.

Ahlfeldt, G. M., \& Kavetsos, G. (2013). Form or Function? The impact of new sports stadia on property prices in London. Journal of the Royal Statistical Society A, 176.

Ahlfeldt, G. M., \& Maennig, W. (2010). Substitutability and Complementarity of Urban Amenities: External Effects of Built Heritage in Berlin. Real Estate Economics, 38(2), 285-323.

Ahlfeldt, G. M., Redding, S. J., Sturm, D. M., \& Wolf, N. (2012). The Economics of Density: Evidence from the Berlin Wall. CEP Discussion Paper No 1154.

Ahlfeldt, G. M., \& Wendland, N. (2013). How polycentric is a monocentric city? Centers, spillovers and hysteresis. Journal of Economic Geography, 13(1), 53-83.

Albouy, D. (2009). What are cities worth? Land rents, local productivity, and the capitalization of amenity values. NBER Working Paper 14981.

Albouy, D. (2012). Are Big Cities Bad Places to Live? Estimating Quality of Life across Metropolitan Areas. Working Paper.

Angrist, J. D., \& Pischke, J.-S. (2009). Mostly Harmless Econometrics: An Empiricist's Companion. Princeton, New Jersey: Princton University Press.

Asabere, P. K., Huffman, F. E., \& Mehdian, S. (1994). The Adverse Impacts of Local Historic Designation: The Case of Small Apartment Buildings in Philadelphia. Journal of Real Estate Finance \& Economics, 8(3), 225-234.

Berlin, S. (1992). 18. Bericht über Stadterneuerung.

Berlin, S. (2001). 22. Bericht über Stadterneuerung.

Berlin, S. (2005). Leitsätze zur Stadterneuerung.

Berlin, S. (2010). 27. Bericht über Stadterneuerung.

Berlin, S. (2012). 28. Bericht über Stadterneuerung.

Blomquist, G. C., Berger, M. C., \& Hoehn, J. P. (1988). New Estimates of Quality of Life in Urban Areas. The American Economic Review, 78(1), 89-107.

Brooks, L., \& Phillips, J. (2007). Inside the Gift Horse's Mouth: City Spending, Political Institutions and the Community Development Block Grant Program. McGill University Working Papers.

Brueckner, J. K., \& Rosenthal, S. S. (2009). Gentrification and Neighborhood Housing Cycles: Will America's Future Downtowns be Rich? The Review of Economics and Statistics, 91(4), 725-743.

Brueckner, J. K., Thisse, J.-F., \& Zenou, Y. (1999). Why Is Central Paris Rich and Downtown Detroit Poor? An Amenity-Based Theory. European Economic Review, 43(1), 91-107.

Brunner, E., \& Sonstelie, J. (2003). Homeowners, property values, and the political economy of the school voucher. Journal of Urban Economics, 54(2), 239-257.

Brunner, E., Sonstelie, J., \& Thayer, M. (2001). Capitalization and the Voucher: An Analysis of Precinct Returns from California's Proposition 174. Journal of Urban Economics, 50(3), 517-536.

Bundesinstitut für Bau, S.-u. R. (2009). Die Städtebauförderungsdatenbank des BBSR.

Caliendo, M., \& Kopeinig, S. (2008). SOME PRACTICAL GUIDANCE FOR THE IMPLEMENTATION OF PROPENSITY SCORE MATCHING. Journal of Economic Surveys, 22(1), 31-72.

Carlino, G. A., \& Coulson, N. E. (2004). Compensating Differentials and the Social Benefits of the NFL. Journal of Urban Economics, 56(1), 25-50.

Carlino, G. A., \& Saiz, A. (2008). City Beautiful. Federal Serve Bank for Philadelphia Working Papers, 08-22, 1-61.

Cellini, S. R., Ferreira, F., \& Rothstein, J. (2010). The value of school facility investments: Evidence from a dynamic regression discontinuity design. The Quarterly Journal of Economics, 125(1), 215-261.

Cheshire, P. C., \& Sheppard, S. (1995). On the Price of Land and the Value of Amenities. [Article]. Economica, 62(246), 247-267.

Ciccone, A. (2002). Agglomeration effects in Europe. European Economic Review, 46(2), 213-227. 
Ciccone, A., \& Hall, R. E. (1996). Productivity and the Density of Economic Activity. American Economic Review, 86(1), 54-70.

Clark, D. E., \& Herrin, W. E. (1997). Historical preservation districts and home sale prices: evidence from the Sacramento housing market. The Review of regional studies, 27, 29-48.

Clay, P. L. (1979). Neighborhood renewal. Middle-class Resettlement and Incumbent Upgrading in American Neighbourhood. Lexington, MA: Lexington Books.

Coulson, N. E., \& Lahr, M. L. (2005). Gracing the Land of Elvis and Beale Street: Historic Designation and Property Values in Memphis. Real Estate Economics, 33(3), 487507.

Coulson, N. E., \& Leichenko, R. M. (2004). Historic preservation and neighbourhood change. Urban Studies, 41(8), 1587-1600.

Dachis, B., Duranton, G., \& Turner, M. A. (2012). The effects of land transfer taxes on real estate markets: evidence from a natural experiment in Toronto. Journal of Economic Geography, 12(2), 327-354.

Dehring, C. A., Depken, C. A., \& Ward, M. R. (2008). A direct test of the homevoter hypothesis. Journal of Urban Economics, 64(1), 155-170.

DiPasquale, D., \& Glaeser, E. L. (1999). Incentives and Social Capital: Are Homeowners Better Citizens? Journal of Urban Economics, 45(2), 354-384.

Florida, R. (2002). The Rise of the Creative Class - and how it's Transforming Work, Leisure, Community and Everyday Life. New York: Basic Books.

Gabriel, S. A., \& Rosenthal, S. S. (2004). Quality of the Business Environment Versus Quality of Life: Do Firms and Households Like the Same Cities? The Review of Economics and Statistics, 86(1), 483.

Galster, G. C. (1983). Empirical Evidence on Cross-Tenure Differences in Home Maintenance and Conditions. Land Economics, 59(1), 107-113.

Gibbons, S., \& Machin, S. (2005). Valuing rail access using transport innovations. Journal of Urban Economics, 57(1), 148-169.

Glaeser, E. L., Hedi, D. K., Jose, A. S., \& Andrei, S. (1992). Growth in Cities. Journal of Political Economy, 100(6), 1126-1152.

Glaeser, E. L., Kolko, J., \& Saiz, A. (2001). Consumer city. Journal of Economic Geography, 1(1), 27-50.

Glaeser, E. L., \& Mare, D. C. (2001). Cities and Skills. Journal of Labor Economics, 19(2), 316-342.

Gyourko, J., \& Tracy, J. (1991). The Structure of Local Public Finance and the Quality of Life. Journal of Political Economy, 99(4), 774-806.

Halvorsen, R., \& Palmquist, R. (1980). The Interpretation of Dummy Variables in Semilogarithmic Equations. American Economic Review, 70(3), 474-475.

Hilber, C. A. L. (2010). New housing supply and the dilution of social capital. Journal of Urban Economics, 67(3), 419-437.

Holman, N., \& Ahlfeldt, G. M. (2013). No escape? The coordination problem in heritage preservation. SERC Discussion Paper 145.

Ioannides, Y. M. (2003). Interactive property valuations. Journal of Urban Economics, 53(1), 145-170.

Koster, H. R. A., \& Van Ommeren, J. N. (2013). Spatial Externalities and Place-Based Policies: Evidence from the Netherlands. Paper presented at the ERSA 2013 Conference.

Koster, H. R. A., Van Ommeren, J. N., \& Rietveld, P. (2012). Upscale Neighbourhoods: Historic Amenities, Income and Spatial Sorting of Households. Mimeo, VU Unversity Amsterdam.

Krugman, P. (1991). History and Industry Location: The Case of the Manufacturing Belt. The American Economic Review, 81(2), 80-83.

Krugman, P. (1994). Complex Landscapes in Economic Geography. The American Economic Review, 84(2), 412-416.

Lazrak, F., Nijkamp, P., Rietveld, P., \& Rouwendal, J. (2010). The market value of listed heritage: An urban economic application of spatial hedonic pricing. VU University Amsterdam Working http://www.tinbergen.nl/files/papers/flpnprir laatste versie okt 2010.pdf.

Lee, S., \& Lin, J. (2012). Neihborhood Dynamics and Natural Amenities. Working Paper. 
Leichenko, R. M., Coulson, N. E., \& Listokin, D. (2001). Historic Preservation and Residential Property Values: An Analysis of Texas Cities. Urban Studies, 38(11), 1973-1987.

LeRoy, S. F., \& Sonstelie, J. (1983). Paradise lost and regained: Transportation innovation, income, and residential location. Journal of Urban Economics, 13(1), 67-89.

Listokin, D., Listokin, B., \& Lahr, M. (1998). The Contributions of Historic Preservation to Housing and Economic Development. Housing Policy Debate, 9(3), 431-478.

Lucas, R. E., Jr., \& Rossi-Hansberg, E. (2002). On the Internal Structure of Cities. Econometrica, 70(4), 1445-1476.

Maennig, W. (2012). Monument Protection and Zoning: Regulations and Public Support from an International Perspective. In T. Just \& W. Maennig (Eds.), Understanding German Real Estate Markets (pp. 181-192). Berlin Heidelberg: Springer

Noonan, D. S., \& Krupka, D. J. (2011). Making-or Picking-Winners: Evidence of Internal and External Price Effects in Historic Preservation Policies. Real Estate Economics, 39(2), 379-407.

Oates, W. E. (1969). The Effects of Property Taxes and Local Public Spending on Property Values: An Empirical Study of Tax Capitalization and the Tiebout Hypothesis. Journal of Political Economy, 77(6), 957-971.

Rauch, J. E. (1993). Productivity Gains from Geographic Concentration of Human Capital: Evidence from the Cities. Journal of Urban Economics, 34(3), 380-400.

Redding, S. J., \& Sturm, D. M. (2008). The costs of remoteness: evidence from German division and reunification. American Economic Review, 98(5), 1766-1797.

Roback, J. (1982). Wages, Rents, and the Quality of Life. Journal of Political Economy, 90(6), 1257-1278.

Rosen, S. (1974). Hedonic Prices and Implicit Markets: Product Differentiation in Pure Competition. Journal of Political Economy, 82(1), 34-55.

Rosenbaum, P. R., \& Rubin, D. B. (1983). The Central Role of the Propensity Score in Observational Studies for Causal Effects. Biometrika, 70(1), 41-55.

Rosenthal, S. S., \& Strange, W. C. (2001). The Determinants of Agglomeration. Journal of Urban Economics, 50(2), 191-229.

Rossi-Hansberg, E., Sarte, P.-D., \& Owens, R. (2010). Housing Externalities. Journal of Political Economy, 118(3), 485-535.

Schaeffer, P. V., \& Millerick, C. A. (1991). The impact of historic district designation on property values: An empirical study. Economic Development Quarterly, 5(4), 301312.

Schwartz, A. E., Ellen, I. G., Voicu, I., \& Schill, M. H. (2006). The external effects of placebased subsidized housing. Regional Science and Urban Economics, 36(6), 679707.

Senatsverwaltung für Stadtentwicklung Berlin. (2006). Urban and Environmental Information System. Berlin.

Silverman, B. W. (1986). Density Estimation For Statistics and Data Analysis. Monographs on Statistics and Applied Probability.

Tabuchi, T., \& Yoshida, A. (2000). Separating Urban Agglomeration Economies in Consumption and Production. Journal of Urban Economics, 48(1), 70-84. 
Gabriel M. Ahlfeldt*, Wolfgang Maennig^ \& Felix J. Richter

\section{Technical appendix to:}

\section{"Urban Renewal after the Berlin Wall"}

Version: November 2013

\section{Introduction}

This technical appendix complements the main paper by providing complementary evidence and additional detail on the data used. The appendix is not designed to stand alone or replace the main paper. Section 2 adds to the empirical strategy and data section of the main paper, providing additional detail on the renewal areas and the control groups and data. Section 3 provides complementary evidence that extends the results in section 4 of the main paper. To improve readability, the respective sections of the main paper are partially replicated.

\section{Data}

This section provides additional information on the studied areas and descriptive evidence not reported in the main paper to save space.

\subsection{Renewal and Investigation Areas}

This (sub) section presents the studied areas in greater detail. To convey an understanding of the size and form of the relevant space, Figure 1 in the main paper depicts the renewal and investigation areas. Figure A1 provides a more detailed picture of a cluster of renewal areas (grey) in East Berlin. Investigation areas that were partially transformed into renewal areas are hatched (diagonal parallel lines). It is reassuring that the matched

* London School of Economics (LSE), Department of Geography and Environment \& Spatial Economics Research Centre (SERC), Houghton Street, London WC2A 2AE, g.ahlfeldt@lse.ac.uk, www.ahlfeldt.com

^ University of Hamburg, Department of Economics, Von Melle Park 5, 20146 Hamburg, wolfgang.maennig@wiso.uni-hamburg.de, www.uni-hamburg.de/economicpolicy

- University of Hamburg, Department of Economics, Von Melle Park 5, 20146 Hamburg, fe$\underline{\text { lix.richter@wiso.uni-hamburg.de, www.uni-hamburg.de/economicpolicy }}$ 
observations (red X) and the investigation areas cover similar areas (if outside the $500 \mathrm{~m}$ buffer), while geographically proximate but structurally different areas (for example Wedding) are underrepresented. Some technical details on the matching technique are discussed in the next subsection.

In Table A1, we present some additional descriptive statistics on the renewal areas including exact dates of beginning and end of the designation, number of housing units and properties and population.

Fig. A1. Snapshot Renewal Areas

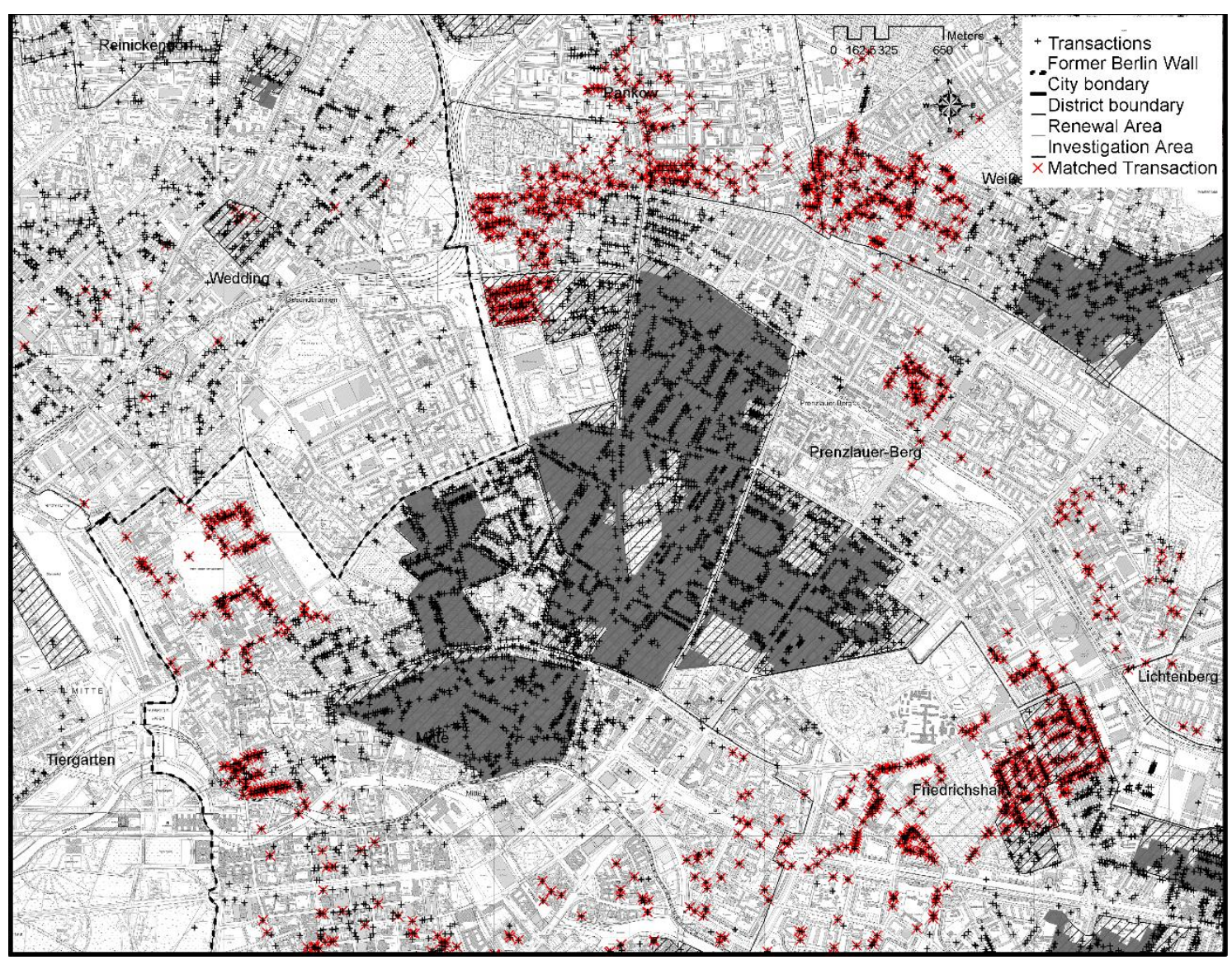

Notes: Own illustration based on the urban and environmental information system (Senatsverwaltung für Stadtentwicklung Berlin, 2006). Dark shaded (hatched) areas indicate renewal (investigation) areas. Black (red) crosses indicate (matched) transactions (in CG 4a). 
Tab A1. Descriptive Statistics Renewal Areas

\begin{tabular}{lllllll}
\hline & & & & dwelling & \\
Name & start & end & area $(\mathrm{km} 2)$ & properties & units & residents \\
\hline Samariterviertel & 09.10 .1993 & 10.02 .2008 & 0.339 & 263 & 5302 & 8324 \\
Warschauer Strasse & 04.12 .1994 & 28.04 .2011 & 0.381 & 227 & 5110 & 8599 \\
Traveplatz Ostkreuz & 04.12 .1994 & 11.07 .2010 & 0.351 & 204 & 4380 & 6964 \\
Kaskelstrasse & 04.12 .1994 & 10.02 .2008 & 0.221 & 248 & 1665 & 3394 \\
Weitlingstrasse & 04.12 .1994 & 28.01 .2009 & 0.503 & 331 & 4214 & 5337 \\
Spandauer Vorstadt & 09.10 .1993 & 10.02 .2008 & 0.671 & 632 & 5809 & 8771 \\
Beusselstrasse & 04.12 .1994 & 21.02 .2007 & 0.106 & 93 & 2314 & 3045 \\
Rosenthaler Vorstadt & 04.12 .1994 & 28.01 .2009 & 0.376 & 373 & 4809 & 6794 \\
Stephankiez & 10.11 .1995 & 21.02 .2007 & 0.063 & 54 & 1288 & 1860 \\
Soldiner Strasse & 10.11 .1995 & 21.02 .2007 & 0.019 & 11 & 447 & 661 \\
Wederstrasse & 10.11 .1995 & 11.07 .2010 & 0.246 & 233 & 1341 & 2079 \\
Kottbusser Damm Ost & 10.11 .1995 & 21.02 .2007 & 0.025 & 21 & 380 & 522 \\
Kollwitzplatz & 09.10 .1993 & 28.01 .2009 & 0.607 & 476 & 6519 & 11412 \\
Helmholtzplatz & 09.10 .1993 & & 0.819 & 560 & 13338 & 21211 \\
Winsstrasse & 04.12 .1994 & 28.04 .2011 & 0.348 & 219 & 4850 & 8568 \\
Wollankstrasse & 04.12 .1994 & 28.04 .2011 & 0.685 & 338 & 3386 & 7719 \\
Teutoburger Platz & 04.12 .1994 & 12.02 .2013 & 0.498 & 316 & 4432 & 7950 \\
Komponistenviertel & 04.12 .1994 & 11.07 .2010 & 0.339 & 477 & 3443 & 7400 \\
Boetzowstrasse & 10.11 .1995 & 28.04 .2011 & 0.381 & 191 & 3072 & 6211 \\
Altstadt Kiez Vorstadt & 09.10 .1993 & 21.02 .2007 & 0.351 & 225 & 1105 & 2115 \\
Niederschöneweide & 04.12 .1994 & & 0.221 & 97 & 799 & 1368 \\
Oberschöneweide & 10.11 .1995 & 11.07 .2010 & 0.503 & 255 & 3465 & 5375 \\
\hline
\end{tabular}

Notes: The data for area, properties, dwelling units, and residents are from the Berlin administrative unit for urban development and environment (Senatsverwaltung für Stadtentwicklung und Umwelt, 2007). The Renewal Area "Teutoburger Platz" was deregulated after the end of our observation period (August 2012). The data for the areas "Komponistenviertel" and "Niederschöneweide" are from 2010.

Table A2 provides a comparison of the renewal areas, the investigation areas and the rest of Berlin. While there are some differences, the structural similarities between the renewal areas and the investigation areas are striking when compared to the rest of Berlin. The housing stock is much older than in the rest of Berlin, and the floor space index is higher. The reason is, in part, that single-family houses are practically not existent in the in the centrally located renewal and investigation areas, while naturally abundant in the peripheral parts of the rest of the city. The takeaway is that the renewal areas and the investigation areas are relatively homogenous areas dominated by buildings constructed around the turn of the $19^{\text {th }}$ and $20^{\text {th }}$ centuries (the so called founding period / "Gründerzeit"). These are primarily apartment blocks, often with some commercial units on the ground floor. 
Tab A2. Comparative Statistics

\begin{tabular}{llll}
\hline & & & Rest of Berlin (without RE- \\
& Renewal Areas & Investigation Areas & NEWAL / INVEST ) \\
\hline Price (cpi adjusted) & $€ 1,490,795.00$ & $€ 1,382,921.00$ & $€ 1,503,588.00$ \\
& $(€ 3,290,749.00)$ & $(€ 1,548,053.00)$ & $(€ 5,667,000.00)$ \\
Age & 101.5 & 96.0 & 60.3 \\
& $(22.8)$ & $(23.6)$ & $(36.5)$ \\
Floor space index & 2.609 & 2.902 & 1.127 \\
& $(0.981)$ & $(1.074)$ & $(1.230)$ \\
Average plot size & 1058 & 1003 & 1798 \\
& $(1834)$ & $(1481)$ & $(6515)$ \\
Share of foreigners & 0.14 & 0.17 & 0.11 \\
& $(0.14)$ & $(0.11)$ & $(0.13)$ \\
Single family home (\%) & 0.35 & 1.35 & 46.26 \\
Apartment / buildings (\%) & 29.67 & 37.39 & 19.39 \\
Mixed use buildings (\%) & 62.05 & 55.35 & 19.02 \\
Commercial buildings (\%) & 3.69 & 1.68 & 2.35 \\
\hline
\end{tabular}

Notes: Prices are in 2012 Euros

\subsection{Control Groups}

This section discusses the different control groups and presents some technical details on the creation of control groups $4 \mathrm{a}$ and $4 \mathrm{~b}$. Overall, we observe approximately 71,000 transactions between 1990 and 2012 in Berlin, with between 2,200 and 6,000 observations per year. Of these transactions, 4,500 occurred inside our renewal areas. The transactions are compared to varying control groups, where the direct surroundings within a $500 \mathrm{~m}$ buffer of each renewal area are excluded from every control group. The rationale is to ensure that the counterfactual provided by the control groups is not contaminated by spillover effects. The first control group (1a) comprises all other transactions (outside the $500 \mathrm{~m}$ buffer) and the second (2a) all transactions in a 500-2,000 meter radius. Control group (3a) consists of the fractions of the investigation areas outside the $500 \mathrm{~m}$ buffer and includes approximately 4,000 transactions. The matching procedure discussed below results in 4,200 transactions that are matched to our renewal area transactions (Control Group 4a). In the second step, we observe 6,600 transactions that are located in a 500 meter radius around the renewal areas and compare them to all other transactions $(1 \mathrm{~b})^{1}$, all transactions in a 500 to 2,000 meter radius around the renewal areas (Control group 2b, 12,800 obs.), the investigation areas plus a 1,000 meter buffer around them (Control group 3b, 10,200 obs.), and to the matched observations discussed below (Control group 4b, 10,300 obs.).

1 Transactions inside the renewal areas are completely excluded from the sample in the second step. 
We generate control groups $4 \mathrm{a} \& 4 \mathrm{~b}$ using a synthetic matching technique: We use the propensity score matching methodology advanced by Rosenbaum \& Rubin (1983) to find observations that are structurally similar to the transactions in the renewal areas (4a) and the transactions in a 500 meter radius around the renewal areas (4b). For the estimation of the internal effects (models 4, 6, and 10, Table 1), we include the following covariates: age of the building, building type, location quality, typical area floor space index, distance to the nearest park, main street, playground, waterway, and public transport station, latitude and longitude, and a set of dummies controlling for land use and east / west location. For the external effects (models 4 and 6, Table 2), we include age, building type, location quality, building structure, location characteristics, and distance to the nearest main street. In both cases, we match the treatment group to the control group using nearest neighbor matching. The matching process creates subsamples, where the difference in means between the treatment and control group is substantially reduced. Tables A3 and A4 report the average treatment effect on the treated (ATT) and several measures of the balance of the covariates for the control groups ( $4 \mathrm{a}$ and $4 \mathrm{~b}$ ). 
Tab A3. Control Group 4a

Average Treatment Effect on the Treated

\begin{tabular}{|c|c|c|c|c|c|}
\hline Sample & Treated & Controls & Difference & S.E. & T-stat \\
\hline Unmatched & 13.418962 & 12.8458767 & 0.5730857 & 0.015963518 & 35.9 \\
\hline ATT & 13.418962 & 13.3384842 & 0.0804782 & 0.021071276 & 3.82 \\
\hline \multicolumn{6}{|l|}{ Balancing of the covariates } \\
\hline Variable & Sample & $\begin{array}{l}\text { Mean } \\
\text { Treated }\end{array}$ & Control & $\begin{array}{l}\text { standardized } \\
\text { bias (\%) }\end{array}$ & $\begin{array}{l}\text { \% reduction } \\
\text { in abs. bias }\end{array}$ \\
\hline \multirow[t]{2}{*}{ Age } & Unmatched & 100.81 & 59.704 & 136.9 & \\
\hline & Matched & 101.5 & 92.186 & 31 & 77.3 \\
\hline \multirow[t]{2}{*}{ Building type } & Unmatched & 4.7429 & 2.7689 & 132 & \\
\hline & Matched & 4.7947 & 4.9221 & -8.5 & 93.5 \\
\hline \multirow[t]{2}{*}{ East / west } & Unmatched & 0.04238 & 0.64936 & -165.7 & \\
\hline & Matched & 0.04264 & 0.07909 & -10 & 94 \\
\hline \multirow[t]{2}{*}{ Longitude } & Unmatched & 27282 & 23782 & 55.4 & \\
\hline & Matched & 27271 & 28781 & -23.9 & 56.8 \\
\hline \multirow[t]{2}{*}{ Latitude } & Unmatched & 21874 & 19423 & 43.9 & \\
\hline & Matched & 21900 & 21080 & 14.7 & 66.5 \\
\hline \multirow[t]{2}{*}{ Location quality } & Unmatched & 2.5171 & 3.7574 & -61.4 & \\
\hline & Matched & 2.7627 & 3.1517 & -19.2 & 68.6 \\
\hline \multirow[t]{2}{*}{ Typical floor space index } & Unmatched & 2.2635 & 1.0455 & 163.9 & \\
\hline & Matched & 2.263 & 1.7998 & 62.3 & 62 \\
\hline \multirow[t]{2}{*}{ Residential area indicator } & Unmatched & 0.86687 & 0.84722 & 5.6 & \\
\hline & Matched & 0.9545 & 0.90186 & 15 & -167.9 \\
\hline \multirow[t]{2}{*}{ Commercial area indicator } & Unmatched & 0.02761 & 0.01855 & 6 & \\
\hline & Matched & 0.02978 & 0.06051 & -20.5 & -239.1 \\
\hline \multirow[t]{2}{*}{ Distance to CBD } & Unmatched & 4705.4 & 9250.6 & -120.3 & \\
\hline & Matched & 4697 & 6698.9 & -53 & 56 \\
\hline \multirow[t]{2}{*}{ Distance to park } & Unmatched & 2138.2 & 1695.4 & 39 & \\
\hline & Matched & 2132.2 & 1801.8 & 29.1 & 25.4 \\
\hline \multirow[t]{2}{*}{ Distance to main street } & Unmatched & 127.43 & 198.62 & -40.4 & \\
\hline & Matched & 127.63 & 125.6 & 1.2 & 97.1 \\
\hline \multirow[t]{2}{*}{ Distance to water } & Unmatched & 1406.7 & 1594.7 & -16.6 & \\
\hline & Matched & 1399.3 & 1192.6 & 18.3 & -10 \\
\hline
\end{tabular}

Notes: The propensity scores are computed using nearest neighbor matching. Following Rosenbaum \& Rubin (1985) and Leuven \& Sianesi (2003), the standardized bias is the difference between the sample means in the sub-samples (treated and control), computed as the percentage of the square root of the average of the sample variances in the treated and control groups. 
Tab A4. Control Group $4 b$

\begin{tabular}{|c|c|c|c|c|c|}
\hline Sample & Treated & Controls & Difference & S.E. & T-stat \\
\hline Unmatched & 13.5304659 & 12.7900137 & 0.7404521 & 0.011078247 & 66.84 \\
\hline ATT & 13.5304659 & 13.7777444 & -0.2472785 & 0.015212132 & -16.26 \\
\hline \multicolumn{6}{|l|}{ Balancing of the covariates } \\
\hline Variable & Sample & $\begin{array}{l}\text { Mean } \\
\text { Treated }\end{array}$ & Control & $\begin{array}{l}\text { standardized } \\
\text { bias (\%) }\end{array}$ & $\begin{array}{l}\text { \% reduction } \\
\text { in abs. bias }\end{array}$ \\
\hline \multirow[t]{2}{*}{ Age } & Unmatched & 87.676 & 56.839 & 90.2 & \\
\hline & Matched & 88.573 & 80.826 & 22.7 & 74.9 \\
\hline \multirow[t]{2}{*}{ Building type } & Unmatched & 4.5572 & 2.6331 & 116.1 & \\
\hline & Matched & 4.557 & 4.6999 & -8.6 & 92.6 \\
\hline \multirow[t]{2}{*}{ Location quality } & Unmatched & 2.7652 & 3.8524 & -51.8 & \\
\hline & Matched & 2.9681 & 3.4993 & -25.3 & 51.1 \\
\hline \multirow[t]{2}{*}{ Typical floor space index } & Unmatched & 2.1696 & 0.93918 & 149.7 & \\
\hline & Matched & 2.1696 & 2.0385 & 16 & 89.3 \\
\hline \multirow[t]{2}{*}{ Residential area indicator } & Unmatched & 0.81127 & 0.8462 & -9.3 & \\
\hline & Matched & 0.89713 & 0.85686 & 10.7 & -15.3 \\
\hline \multirow[t]{2}{*}{ Commercial area indicator } & Unmatched & 0.03934 & 0.02194 & 10.1 & \\
\hline & Matched & 0.04305 & 0.06744 & -14.2 & -40.2 \\
\hline \multirow[t]{2}{*}{ Distance to CBD } & Unmatched & 5006.4 & 9667.8 & -121.5 & \\
\hline & Matched & 4980.7 & 5402.4 & -11 & 91 \\
\hline \multirow[t]{2}{*}{ Distance to park } & Unmatched & 2302.5 & 1595.4 & 55.4 & \\
\hline & Matched & 2293.1 & 1973 & 25.1 & 54.7 \\
\hline \multirow[t]{2}{*}{ Distance to main street } & Unmatched & 125.19 & 208.07 & -45.2 & \\
\hline & Matched & 125.12 & 115.84 & 5.1 & 88.8 \\
\hline \multirow[t]{2}{*}{ Distance to water } & Unmatched & 1245.7 & 1626.5 & -32.4 & \\
\hline & Matched & 1245.9 & 1200.5 & 3.9 & 88.1 \\
\hline
\end{tabular}

Notes: The propensity scores are computed using nearest neighbor matching. Following Rosenbaum and Rubin (1985) and Leuven and Sianesi (2003), the standardized bias is the difference in the sample means in the sub-samples (treated and control) as the percentage of the square root of the average of the sample variances in the treated and control groups.

\subsection{Maintenance Trends}

This section further adds to section 3.4., complementing the conditional mean shares analysis of the maintenance trends. As mentioned in the notes to Figure 2 in the main paper, we estimate two separate regressions of the type:

$$
Y_{i t}=\sum_{t} \beth_{t} T_{i} \times \varphi_{t}+\sum_{o} X_{o t}+\varphi_{t}+\epsilon_{i t}
$$

where $Y_{i t}$ indicates whether a property at time $t$ was in good or poor maintenance condition. In Figure A2, we vary the vector $X_{o t}$ by including or excluding additional covariates and the control groups (CG) to which we compare the transactions in the renewal areas. Thus, $\mathrm{T}_{\mathrm{i}}$ is an indicator variable indicating whether a property falls within a renewal area $(\mathrm{T}=1)$ or a control group area $(\mathrm{T}=0)$. The first column presents the results for an empty model where we exclude $X_{o t}$ completely (the unconditional share), in the second row we add land use dummies and buyer / seller type indicators to the benchmark model covariates. In row 3, we employ the same covariates as in the main paper, but instead of compar- 
ing the conditional shares in renewal areas to the shares in all investigation areas, we compare them to the overall share in Berlin. The results are relatively insensitive to these alternations at least in qualitative terms: Over the designation period, the share of buildings in good condition increases in the renewal areas relative to other areas, while the share of buildings in poor condition decreases.

Fig. A2. Maintenance Trends

Condition Good

Empty model, CG 3

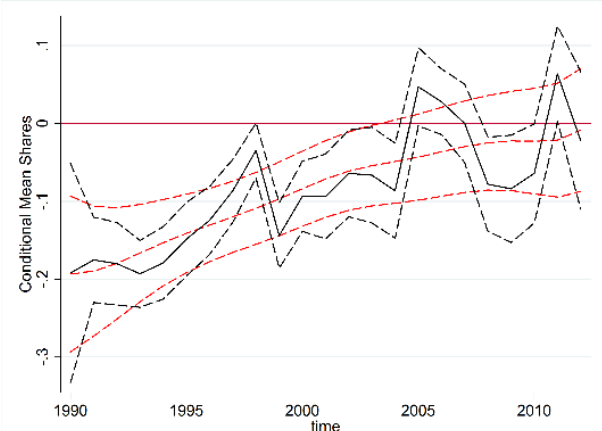

Full model, CG 3

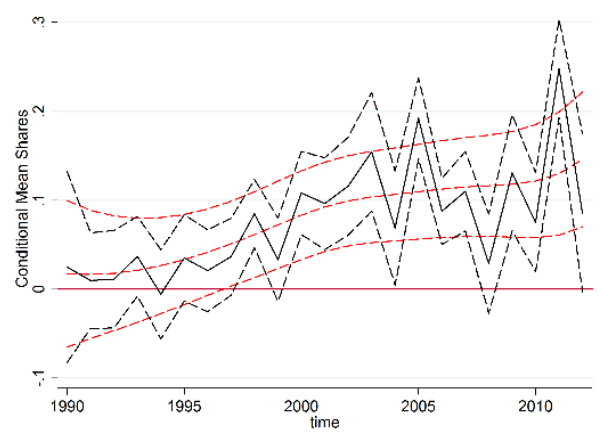

Benchmark model, CG 1

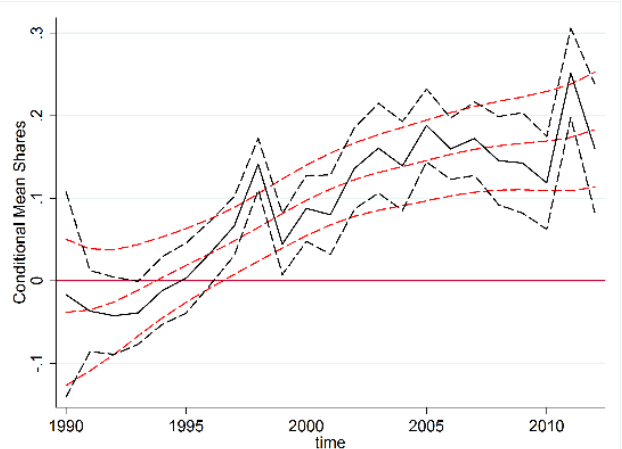

\section{Condition Bad}

Empty model, CG 3

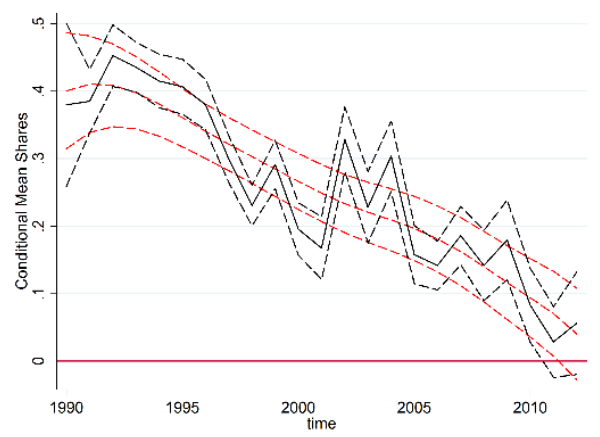

Full model, CG 3

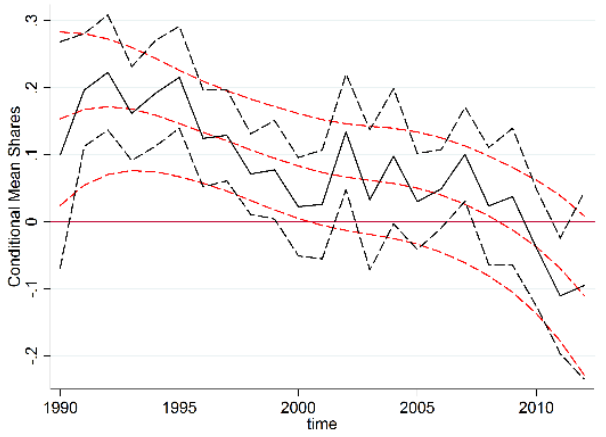

Benchmark model, CG 1

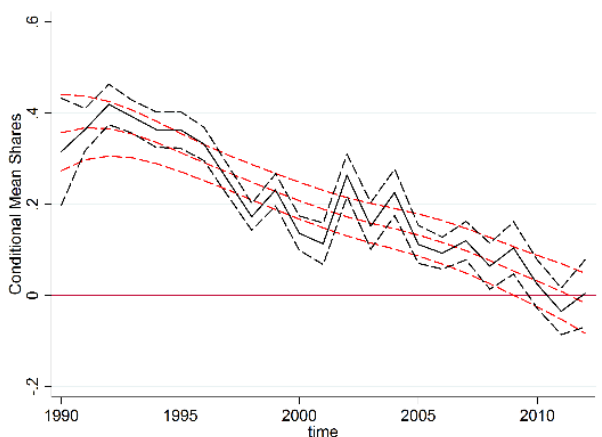

Notes: Black solid (dashed) lines indicate treatment point estimates ( $95 \%$ confidence intervals). Red dashed lines are lowess smoothes of the parameters. 


\section{Empirical Results}

This section complements section 4 of the main paper. The first sub-section provides an overview over the variables and presents some of the estimation results omitted in the main paper. Section 3.2 discusses the possible designation effects on the runner-up areas that remained unconsidered. In section 3.3, we replicate our benchmark results using an urban amenity density measure based on historic data. Section 3.4 provides estimates of spillover effects controlling for building quality, while section 3.5 introduces a spatiotemporal structure into the spillover effects. In section 3.6, we provide a sensitivity analysis of out treatment estimates with respect to the number of areas included in the treatment and control groups as well as an analysis of heterogeneity in the effect across the treated areas. Finally, section 3.7 discusses the aggregated capitalization effect of the policy.

\subsection{Complete results}

Table A5 provides descriptive statistics for all structural and locational variables. Table A6 extends Table 1 in the main paper by presenting the implicit hedonic prices of the structural characteristics.

Tab A5. Descriptive statistics

\begin{tabular}{lllll}
\hline Variable & Mean & Std. Dev. & Min & Max \\
\hline Price (constant 2012 €) & $1,495,060$ & $5,356,786$ & 16,631 & $299,000,000$ \\
Plotarea $\left(\mathrm{m}^{2}\right.$ ) & 1682.062 & 6086.808 & 150 & 205222 \\
Floor space index & 1915.712 & 6105.441 & 65 & 191375 \\
Age (years) & 65.51245 & 37.42346 & 0 & 294 \\
Age squared & 5692.38 & 4857.659 & 0 & 86436 \\
West / east indicator & 0.6099851 & 0.4877562 & 0 & 1 \\
Residential area indicator & 0.8415044 & 0.3652073 & 0 & 1 \\
Commercial area indicator & 0.0287225 & 0.1670266 & 0 & 1 \\
industrial area indicator & 0.0323323 & 0.1768823 & 0 & 1 \\
Distance to main street (m) & 182.3591 & 207.0289 & 0 & 2140.739 \\
Distance to public transport (m) & 980.7227 & 988.5591 & 10.0361 & 9381.628 \\
Distance to open water (m) & 1515.542 & 1297.361 & 0 & 8316.602 \\
Distance to park (m) & 1786.17 & 1377.644 & 0 & 5972.606 \\
Distance to playground (m) & 325.5659 & 318.355 & 10.34 & 6209.051 \\
Distance to listed building building (m) & 230.9044 & 270.7093 & 0.2341669 & 2829.887 \\
Street noise level & 57.42288 & 9.529247 & 15.0819 & 94.5513 \\
Location within block & & & & \\
Building at street front (\%) & 73.34 & & & \\
Building at a corner (\%) & 13.98 & & & \\
Building with multiple fronts (\%) & 3.89 & & & \\
Hammer type Building (\%) & 1.41 & & & \\
Building in inner block loc. (\%) & 6.66 & & & \\
Other (\%) & 4.61 & & & \\
\hline
\end{tabular}


Tab A6. Complete Results

\begin{tabular}{|c|c|c|c|c|c|c|}
\hline \multirow[t]{4}{*}{ Control group } & $1 a$ & $2 a$ & $3 a$ & $4 a$ & $3 a$ & $4 a$ \\
\hline & All & All $<2 \mathrm{~km}$ & $\begin{array}{l}\text { Investiga- } \\
\text { tion Areas }\end{array}$ & $\begin{array}{l}\text { Matched } \\
\text { Observa- } \\
\text { tions }\end{array}$ & $\begin{array}{l}\text { Investigation } \\
\text { Areas }\end{array}$ & $\begin{array}{l}\text { Matched } \\
\text { Observa- } \\
\text { tions }\end{array}$ \\
\hline & \multicolumn{6}{|c|}{ All properties } \\
\hline & 1 & 2 & 3 & 4 & 5 & 6 \\
\hline$T \times P O S T$ & $-0.162 * * *$ & $-0.115 * * *$ & -0.060 & $-0.139 * * *$ & $-0.120 * * *$ & -0.026 \\
\hline (renewal) & $(0.036)$ & (0.037) & (0.039) & $(0.052)$ & $(0.045)$ & $(0.061)$ \\
\hline$T x V$ (years & $0.047 * * *$ & $0.039 * * *$ & $0.023 * * *$ & $0.025 * * *$ & $0.010 * * *$ & 0.005 \\
\hline since des.) & (0.003) & (0.004) & (0.004) & (0.004) & (0.004) & (0.005) \\
\hline \multirow[t]{2}{*}{ Building age } & $-0.014 * * *$ & $-0.012 * * *$ & $-0.012 * * *$ & $-0.011 * * *$ & $-0.012 * * *$ & $-0.010 * * *$ \\
\hline & $(0.001)$ & (0.001) & $(0.002)$ & $(0.002)$ & $(0.002)$ & $(0.002)$ \\
\hline Building age, & $0.000 * * *$ & $0.000 * * *$ & $0.000 * * *$ & $0.000 * * *$ & $0.000 * * *$ & $0.000 * *$ \\
\hline squared & $(0.000)$ & $(0.000)$ & $(0.000)$ & $(0.000)$ & (0.000) & $(0.000)$ \\
\hline Industrial & $0.128^{*}$ & -0.112 & 0.127 & 0.257 & 0.147 & $0.408^{*}$ \\
\hline area indicator & $(0.072)$ & $(0.106)$ & $(0.172)$ & $(0.221)$ & $(0.174)$ & $(0.243)$ \\
\hline Residential & 0.022 & -0.084 & 0.019 & 0.035 & 0.043 & 0.163 \\
\hline area indicator & $(0.048)$ & $(0.079)$ & $(0.120)$ & $(0.147)$ & $(0.114)$ & (0.159) \\
\hline Commercial & $0.356 * * *$ & $0.221 * *$ & $0.256^{*}$ & $0.336^{*}$ & 0.219 & $0.427^{* *}$ \\
\hline use indicator & $(0.061)$ & $(0.089)$ & $(0.151)$ & $(0.172)$ & $(0.147)$ & $(0.184)$ \\
\hline \multirow{2}{*}{ Plot area } & $0.000 * *$ & 0.000 & 0.000 & $0.000 * *$ & -0.000 & $0.000^{*}$ \\
\hline & $(0.000)$ & $(0.000)$ & $(0.000)$ & $(0.000)$ & $(0.000)$ & $(0.000)$ \\
\hline \multirow[t]{2}{*}{ Floorspace } & $0.000 * * *$ & $0.000 * * *$ & $0.000 * * *$ & $0.000 * *$ & $0.000 * * *$ & $0.000 * *$ \\
\hline & $(0.000)$ & $(0.000)$ & $(0.000)$ & $(0.000)$ & $(0.000)$ & $(0.000)$ \\
\hline Building at a & $0.208 * * *$ & $0.236 * * *$ & $0.219 * *$ & $0.322 * * *$ & $0.223 * *$ & $0.311 * * *$ \\
\hline corner & $(0.041)$ & $(0.066)$ & $(0.104)$ & $(0.106)$ & $(0.102)$ & $(0.104)$ \\
\hline Build. with & $0.348^{* * *}$ & 0.117 & 0.168 & 0.073 & 0.194 & 0.090 \\
\hline mult. fronts & $(0.065)$ & $(0.102)$ & $(0.156)$ & $(0.162)$ & $(0.152)$ & $(0.160)$ \\
\hline Hammer type & $-0.107^{* *}$ & -0.206 & -0.087 & -0.446 & -0.098 & -0.445 \\
\hline Building & $(0.043)$ & $(0.133)$ & $(0.258)$ & $(0.336)$ & $(0.326)$ & $(0.310)$ \\
\hline Build. in inner & $-0.131 * * *$ & $-0.270 * * *$ & $-0.381 * * *$ & $-0.420 * * *$ & $-0.432 * * *$ & $-0.470 * * *$ \\
\hline block loc. & $(0.042)$ & $(0.085)$ & $(0.146)$ & $(0.147)$ & $(0.145)$ & $(0.147)$ \\
\hline Observations & 64,677 & 17,447 & 8,623 & 8,860 & 8,623 & 8,860 \\
\hline $\mathrm{R}^{2}$ & 0.802 & 0.772 & 0.632 & 0.710 & 0.677 & 0.735 \\
\hline AIC & $79,932.8$ & $25,276.8$ & $12,349.3$ & $13,477.5$ & $11,776.3$ & $13,224.6$ \\
\hline Hedonic Controls & YES & YES & YES & YES & YES & YES \\
\hline Location controls & YES & YES & YES & YES & YES & YES \\
\hline Traffic Cell E. & YES & YES & YES & YES & YES & YES \\
\hline Year Effects & YES & YES & YES & YES & YES & YES \\
\hline Time-Varying E. & NO & NO & NO & NO & YES & YES \\
\hline
\end{tabular}

Notes: Table continues on next page 
Table continued

\begin{tabular}{|c|c|c|c|c|}
\hline Control group & $1 a$ & $2 a$ & $3 a$ & $4 a$ \\
\hline & All & All $<2 \mathrm{~km}$ & $\begin{array}{l}\text { Investiga- } \\
\text { tion Areas }\end{array}$ & $\begin{array}{l}\text { Matched } \\
\text { Observations }\end{array}$ \\
\hline & Properties & in good cond & dition & \\
\hline & 7 & 8 & 9 & 10 \\
\hline $\mathrm{T} \times \mathrm{POST}$ & 0.008 & -0.070 & 0.084 & 0.500 \\
\hline (renewal) & $(0.338)$ & $(0.416)$ & $(1.063)$ & $(1.232)$ \\
\hline $\mathrm{T} \times \mathrm{V}$ (years & -0.000 & -0.002 & -0.026 & -0.001 \\
\hline since des. & $(0.012)$ & $(0.014)$ & (0.019) & (0.019) \\
\hline Building age & $-0.012 * * *$ & $-0.009 * * *$ & $-0.006^{*}$ & $-0.006^{*}$ \\
\hline & $(0.001)$ & $(0.002)$ & $(0.004)$ & $(0.003)$ \\
\hline Building age, & $0.000 * * *$ & $0.000 * * *$ & 0.000 & 0.000 \\
\hline squared & $(0.000)$ & $(0.000)$ & $(0.000)$ & $(0.000)$ \\
\hline Industrial & 0.172 & 0.013 & -0.692 & . \\
\hline area indicator & $(0.106)$ & $(0.160)$ & $(1.630)$ & . \\
\hline Residential & $0.105^{* *}$ & -0.011 & 0.491 & 0.495 \\
\hline area indicator & $(0.051)$ & $(0.114)$ & (1.108) & $(0.753)$ \\
\hline Commercial & 0.125 & -0.006 & 0.235 & 0.444 \\
\hline use indicator & $(0.143)$ & $(0.209)$ & (1.154) & (0.709) \\
\hline Plot area & $0.000 * * *$ & $0.000 * *$ & -0.000 & $0.000 *$ \\
\hline & $(0.000)$ & $(0.000)$ & $(0.000)$ & $(0.000)$ \\
\hline Floors pace & 0.000 & $0.000 * * *$ & $0.000 * * *$ & $0.000 * * *$ \\
\hline & $(0.000)$ & $(0.000)$ & $(0.000)$ & $(0.000)$ \\
\hline Building at a & $0.154 * *$ & 0.128 & 0.220 & -0.252 \\
\hline corner & $(0.062)$ & $(0.209)$ & $(0.520)$ & $(0.639)$ \\
\hline Build. with & $0.165^{*}$ & -0.393 & -0.675 & -0.963 \\
\hline mult. fronts & (0.099) & $(0.336)$ & $(0.612)$ & $(0.705)$ \\
\hline Hammer type & $-0.110^{*}$ & 0.021 & . & . \\
\hline Building & $(0.064)$ & $(0.210)$ & . & . \\
\hline Build. in inner & -0.064 & -0.138 & -0.480 & -1.011 \\
\hline block loc. & $(0.058)$ & $(0.220)$ & $(0.577)$ & $(0.680)$ \\
\hline Observations & 15,406 & 2,567 & 787 & 948 \\
\hline $\mathrm{R}^{2}$ & 0.917 & 0.941 & 0.863 & 0.890 \\
\hline AIC & $5,491.0$ & $1,475.9$ & 558.9 & 738.4 \\
\hline Hedonic Controls & YES & YES & YES & YES \\
\hline Location Controls & YES & YES & YES & YES \\
\hline Traffic Cell E. & YES & YES & YES & YES \\
\hline Year Effects & YES & YES & YES & YES \\
\hline Time-Varying E. & NO & NO & NO & NO \\
\hline
\end{tabular}

Notes: Standard errors in parentheses. ${ }^{*} \mathrm{p}<0.1,{ }^{* *} \mathrm{p}<0.05,{ }^{* * *} \mathrm{p}<0.01$

Most coefficients are as expected: To mention some examples, plotarea and floor space significantly increase log prices. The land use indicators show, if significant, a positive influence of residential and commercial areas on logprices (relative to manufacturing sites). The age of a building significantly decreases logprices.

\subsection{Designation effects on investigation areas}

One of the identifying assumptions of quasi-experimental research designs is that the control group used to establish a counterfactual must not be affected itself by the analyzed treatment. A control group formed by runner-ups in a selection process would violate this assumption if the selection of those being treated changed the expectation regarding the 
prospect of those remaining untreated. If a positive signal to the treated areas represents a negative signal to the runner-up areas, the estimated treatment effect would be biased in a positive direction. To avoid the potentially problematic direct comparison of the selected renewal areas to the runner-up areas, we benchmark both areas against the matched transactions discussed in Section 2. We define the renewal areas and the investigation areas that remained undesignated as two separate treatment groups and assign all matched transactions outside the investigation areas to the control group. In Table A7, we report the results of two models that are analogous to (4) and (6) in Table 2 in the main paper, except for the added second treatment group (investigation areas). We choose 1995 as a (placebo) treatment date for the investigation areas that were not designated because the last wave of designation occurred in that year, and the decision not to include these areas into the program became definitive. Setting the placebo designation date to one of the nearest renewal areas changes the results only marginally.

The cumulated effects after 20 years for the investigation areas are not statistically different from zero, no matter whether we allow for selected time-varying effects or not. This finding is consistent with the results in Table 2 in the main paper, where the comparison of trends in renewal areas to either the remaining investigation areas or the matched transactions led to similar results. While a negative level shift with a compensating positive trend is found in the model (1), the effect is not robust to the inclusion of time-varying effects. Our preferred model (2) also suggests that the cumulated long-run effect of the renewal areas is not statistically distinguishable from the remaining investigation areas. Taken together, the evidence does not support that the runner-up areas provide an invalid counterfactual. To the contrary, the results provide further evidence that the policy had marginal impact only because the trends within the group of selected and remaining investigation areas are very similar. 
Tab A7. Renewal and investigation areas vs. matched control group

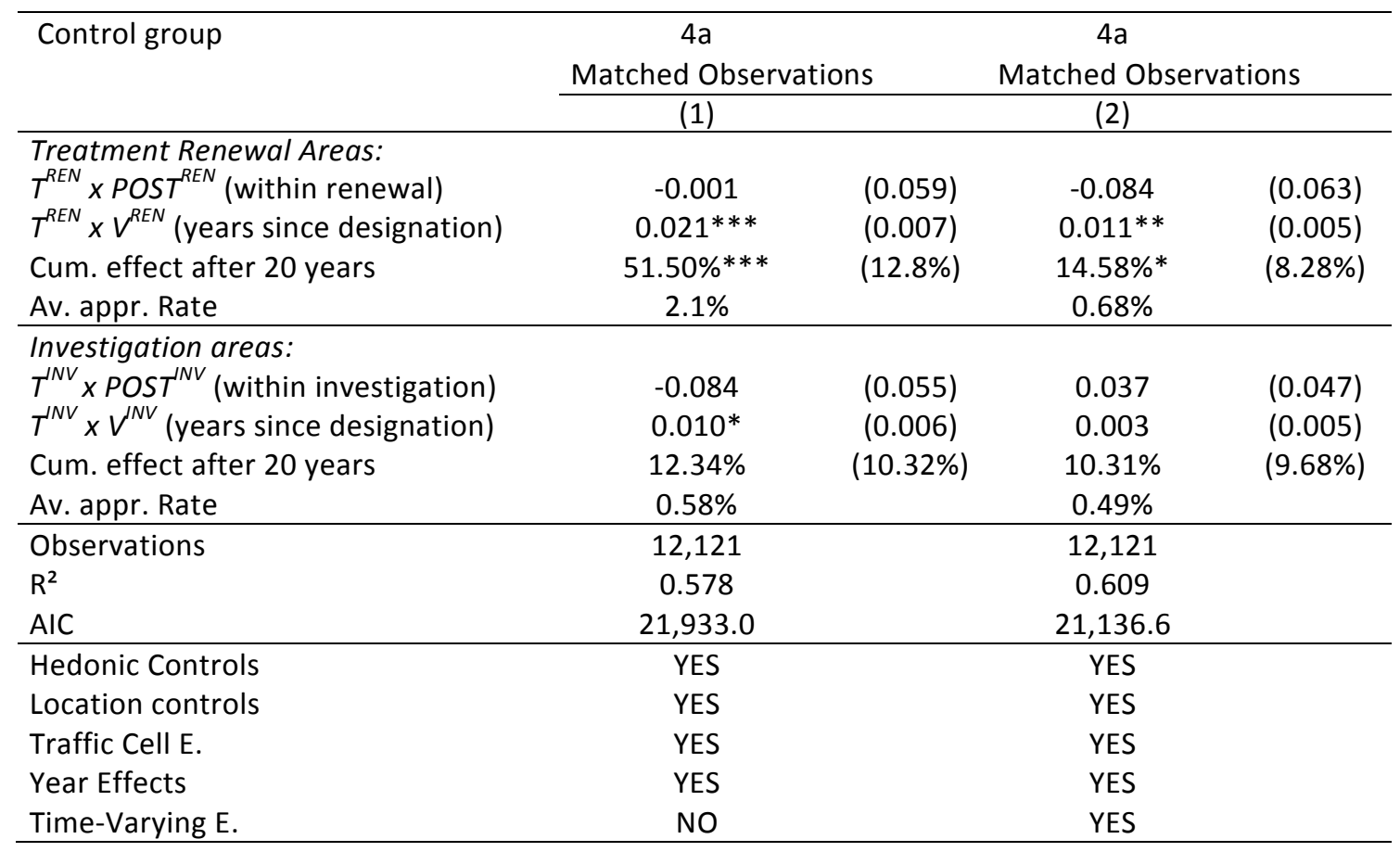

Notes: Standard errors in parentheses. ${ }^{*} \mathrm{p}<0.1{ }^{* *} \mathrm{p}<0.05,{ }^{* * *} \mathrm{p}<0.01$. Hedonic and location controls consist of covariates controlling for internal property and external location characteristics described in greater detail in the data section and the appendix. Time-varying controls are sets of interaction effects of year effects and distance to the CBD, district effects and a consumption amenity measure described in the data section.

\subsection{Historic amenity density}

As outlined in the main paper, we employ a kernel smoothed density surface interacted with year dummies based on the geographic location of bars, pubs, and nightclubs to account for the change in valuation for these urban amenities over time. The rationale behind this approach is that particular districts with great centrality and many urban amenities could have increased in value anyway and that this increase cannot be attributed to the designation of the renewal areas. The data stems from the open street map project and provides a fairly good overview of the distribution of the urban amenities during the study period. One concern, however, is the potential endogeneity of the current (2012) distribution of amenities to the designation of the renewal areas. To address this concern, we provide an alternative approach as a robustness check: we collected data for the distribution of urban amenities for the years 1995 / 96, the first year in which the yellow pages for Berlin reported a zip in a new format that applies to both parts of the formerly divided city and allows for precise geocoding. Figure A3 compares the resulting kernel smoothed density surface (left panel) with the existing density surface displayed in Figure 1 in the main paper (right panel): While there is a slight but notable shift in amenity gravity from the 
south western to the downtown areas, the overall spatial pattern has remained remarkably stable over more than 15 years of convergence to a new post-Berlin Wall equilibrium.

Fig. A3. Kernel smoothed density surfaces comparison
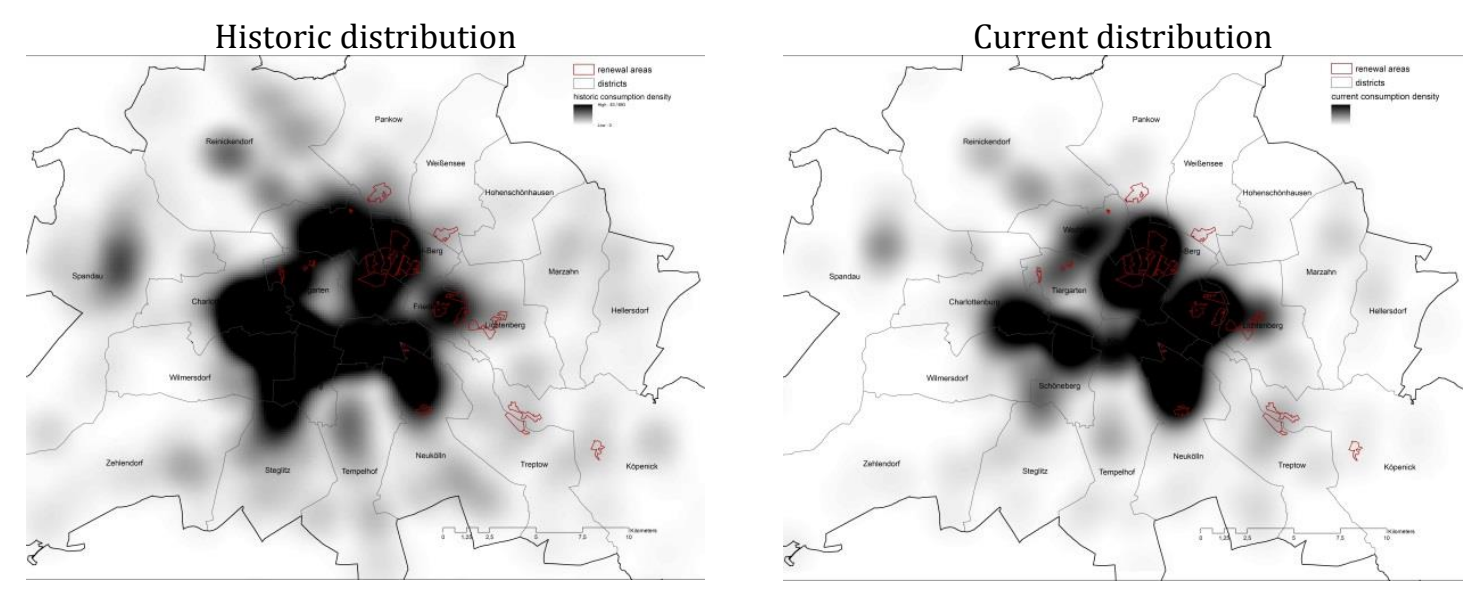

Notes: Notes: Own illustration based on the urban and environmental information system (Senatsverwaltung für Stadtentwicklung Berlin, 2006). Smoothly grey shaded areas represent the consumption amenity density in 1995/96 (left panel) and 2012 (right panel).

Table A8 replicates our primary results using the consumption amenity density depicted in the left panel of Figure A3. Columns 1 and 2 report the effects within renewal areas (internal effects) when compared to the investigation areas and the matched observations; Columns 3 and 4 show the effects on the areas just outside the renewal areas (external effects) compared to the respective control groups. The differences from our primary results are negligible for the internal effects (below 1 percentage point difference after 20 years) and minor for the external effects. As in our main results, no effects are significantly different from zero. 
Tab A8. Internal \& external effects with historic amenities

\begin{tabular}{lcccc}
\hline & \multicolumn{2}{c}{ Internal Effects } & \multicolumn{2}{c}{ External Effects } \\
\hline & 3a & $4 a$ & $3 b$ & $4 b$ \\
\cline { 2 - 5 } & Invest. Areas & $\begin{array}{c}\text { Matched Obser- } \\
\text { vations }\end{array}$ & $\begin{array}{c}\text { Invest. Areas + } \\
1 \text { km buffer }\end{array}$ & $\begin{array}{c}\text { Matched Obser- } \\
\text { vations }\end{array}$ \\
\hline$T \times$ POST & $(1)$ & & & $(3)$ \\
(within renewal) & $-0.113^{* *}$ & -0.015 & -0.042 & $(4)$ \\
$T \times V$ (years & $(0.044)$ & $(0.062)$ & $(0.050)$ & -0.034 \\
since designation) & $0.009 * *$ & 0.005 & 0.002 & $0.064)$ \\
\hline Cum. effect after & $(0.004)$ & $(0.005)$ & $(0.004)$ & $(0.005)$ \\
20 years & $7.97 \%$ & $9.19 \%$ & $-0.21 \%$ & $6.76 \%$ \\
Av. appr. Rate & $(7.15 \%)$ & $(10.73 \%)$ & $(5.07 \%)$ & $(8.24 \%)$ \\
\hline Observations & $0.38 \%$ & $0.44 \%$ & $-0.01 \%$ & $-0.33 \%$ \\
$\mathrm{R}^{2}$ & 8,623 & 8,860 & 11,963 & 16,989 \\
AIC & 0.677 & 0.736 & 0.671 & 0.662 \\
\hline Hedonic Controls & $11,788.5$ & $13,211.7$ & $19,086.1$ & $30,241.7$ \\
Location controls & YES & YES & YES & YES \\
Traffic Cell E. & YES & YES & YES & YES \\
Year Effects & YES & YES & YES & YES \\
Time-Varying E. & YES & YES & YES & YES \\
\hline
\end{tabular}

Notes: Standard errors in parentheses. ${ }^{*} \mathrm{p}<0.1{ }^{* *} \mathrm{p}<0.05,{ }^{* * *} \mathrm{p}<0.01$. Hedonic and location controls consist of covariates controlling for internal property and external location characteristics described in greater detail in the data section and the appendix. Time-varying controls are sets of interaction effects of year effects and distance to the CBD, district effects and a consumption amenity measure described in the data section.

\subsection{External effects including quality controls}

For completeness, we also replicate the estimation of spillover effects including the maintenance indicators (Table A9). The results reported in the main paper are robust to this perturbation. The effects tend to have a similar magnitude and, as expected, we observe strong price effects associated with the physical condition of the building: Properties in good or normal condition generate a large price premium compared to buildings in poor condition. 
Tab A9. External effects including quality controls

\begin{tabular}{|c|c|c|c|c|c|c|}
\hline \multirow[t]{4}{*}{ Control group } & $1 b$ & $2 b$ & $3 b$ & $4 b$ & $3 b$ & $4 b$ \\
\hline & All & $\begin{array}{l}<2 \mathrm{~km} \\
\text { renewal } \\
\text { area buff- } \\
\text { er }\end{array}$ & $\begin{array}{l}\text { Invest. } \\
\text { Areas }+1 \\
\text { km buffer }\end{array}$ & $\begin{array}{l}\text { Matched } \\
\text { Observa- } \\
\text { tions }\end{array}$ & $\begin{array}{l}\text { Invest. } \\
\text { Areas }+1 \\
\text { km buffer }\end{array}$ & $\begin{array}{l}\text { Matched } \\
\text { Observa- } \\
\text { tions }\end{array}$ \\
\hline & \multicolumn{6}{|c|}{500 meter buffer } \\
\hline & $(6)$ & $(7)$ & (8) & (9) & $(10)$ & $(11)$ \\
\hline $\begin{array}{l}T \times P O S T \\
\text { (within renewal) }\end{array}$ & $\begin{array}{l}-0.133^{* * *} \\
(0.050)\end{array}$ & $\begin{array}{l}-0.125^{* *} \\
(0.056)\end{array}$ & $\begin{array}{l}-0.113^{* *} \\
(0.056)\end{array}$ & $\begin{array}{l}-0.104 * \\
(0.054)\end{array}$ & $\begin{array}{l}-0.041 \\
(0.049)\end{array}$ & $\begin{array}{l}-0.094 \\
(0.066)\end{array}$ \\
\hline$T \times V$ (years & $0.017^{* * *}$ & $0.019 * * *$ & $0.019 * * *$ & $0.019 * * *$ & -0.002 & 0.003 \\
\hline since designation) & $(0.003)$ & $(0.003)$ & $(0.003)$ & $(0.004)$ & $(0.004)$ & $(0.005)$ \\
\hline \multirow[t]{2}{*}{ Condition: good } & $0.307^{* * *}$ & $0.567^{* * *}$ & $0.598 * * *$ & $0.500 * * *$ & $0.571 * * *$ & $0.487^{* * *}$ \\
\hline & $(0.015)$ & $(0.036)$ & $(0.036)$ & $(0.034)$ & $(0.034)$ & $(0.031)$ \\
\hline Condition: bad & $\begin{array}{l}-0.283 * * * \\
(0.013)\end{array}$ & $\begin{array}{l}-0.263 * * * \\
(0.021)\end{array}$ & $\begin{array}{l}-0.256 * * * \\
(0.021)\end{array}$ & $\begin{array}{l}-0.290 * * * \\
(0.024)\end{array}$ & $\begin{array}{l}-0.257^{* * *} \\
(0.021)\end{array}$ & $\begin{array}{l}-0.279 * * * \\
(0.023)\end{array}$ \\
\hline Observations & 77,564 & 26,131 & 22,847 & 29,842 & 22,847 & 29,842 \\
\hline $\mathrm{R}^{2}$ & 0.724 & 0.704 & 0.687 & 0.655 & 0.729 & 0.696 \\
\hline AIC & 141,269 & $48,362.4$ & $41,278.9$ & $56,782.8$ & $38,084.7$ & $53,474.5$ \\
\hline Hedonic Controls & YES & YES & YES & YES & YES & YES \\
\hline Location controls & YES & YES & YES & YES & YES & YES \\
\hline Traffic Cell E. & YES & YES & YES & YES & YES & YES \\
\hline Year Effects & YES & YES & YES & YES & YES & YES \\
\hline Time-Varying E. & NO & NO & NO & NO & YES & YES \\
\hline
\end{tabular}

Notes: Standard errors in parentheses. ${ }^{*} \mathrm{p}<0.1$, $^{* *} \mathrm{p}<0.05$, $^{* * *} \mathrm{p}<0.01$

\subsection{Spatio-temporal trends}

As outlined in section 4 in the main paper, one might be concerned that the non-significant spillovers we find are due to a relatively steep spatial decay and, hence, an impact area that is small relative to the $500 \mathrm{~m}$ spillover/buffer area used. We have therefore repeated our approach allowing for spatio-temporal trends. Restricting the sample to the $500 \mathrm{~m}$ buffer area around the renewal areas, we first use a POSTXDIST interaction term between an indicator variable denoting the period after designation (POST) and the distance to the renewal area (DIST) to allow for a change in the spatial trend after the designation. Second, we include YSDXDIST, an interaction between the distance to the nearest renewal area and the years since designation (YSD), allowing for the spatial trend to vary over time. Transactions in renewal areas and beyond the $500 \mathrm{~m}$ buffer are excluded from the sample. The results for both specifications are presented in Table A10. As all relevant coefficients are insignificant, we conclude that that is no significant change in the spatial trend, neither directly after designation, not gradually emerging over the years. 
Tab A10. Spatio-temporal Trends

\begin{tabular}{|c|c|c|c|}
\hline & $\begin{array}{l}\text { (1) } \\
\text { log(price) }\end{array}$ & $\begin{array}{l}\text { (2) } \\
\log \text { (price) }\end{array}$ & \\
\hline POSTxDIST & 0.053 & -0.104 & (0.199) \\
\hline YSDxDIST & & 0.015 & $(0.014)$ \\
\hline YSD & & 0.012 & $(0.029)$ \\
\hline DIST & YES & YES & \\
\hline Hedonic Controls & YES & YES & \\
\hline Location controls & YES & YES & \\
\hline Traffic Cell E. & YES & YES & \\
\hline Year Effects & YES & YES & \\
\hline Time-Varying E. & YES & YES & \\
\hline Observations & 6,636 & 6,636 & \\
\hline $\mathrm{R} 2$ & 0.639 & 0.639 & \\
\hline AIC & $10,345.4$ & $10,343.2$ & \\
\hline
\end{tabular}

\subsection{Sensitivity analysis and treatment heterogeneity}

\section{Sensitivity analysis}

As argued in the main paper, having a large number of available treatment and control areas helps with the evaluation of place-based policies in quasi-experimental research designs because idiosyncratic year-area specific shocks are more likely to then cancel each other out within the groups of treatment and control areas. With its relatively large number of treated and potential control areas, our empirical setting not only allows for a relatively precise estimation of the average treatment effect but also for an evaluation of the sensitivity of the results to the inclusion of smaller numbers of treatment and control areas. As summarized in the main paper, we replicate our preferred model using different combinations of $1,2,5,10,15,20$ and (all) 22 randomly drawn treatment and control areas.

We run three types of experiments. First, we vary the number of treatment areas while using all control areas for comparison. Second, we vary the number of control areas while using all treatment areas. Third, we vary the number of treatment and control areas simultaneously. Naturally, the specification where we draw 22 treatment and 22 control areas corresponds to the benchmark model presented in Table 1 in the main paper. Where a limited number of total combinations exist (e.g., 1x22 treatment areas vs. all control areas or $22 \times 21$ combinations of 2 treatment areas vs. all control areas), we estimate the model for all possible combinations. Where the number of possible combinations is very large, we estimate, for any given combination of numbers of treated and control areas, the 2,500 version of the benchmark model with randomly drawn treatment and / or control areas. 
Figure A4 displays the resulting distributions of the cumulated effect after 20 years summarized in Table 3 in the main paper.

In line with Table 4 in the main paper, Figure A4 reveals a large degree of variation in the point estimates in the models that consider only a small number of treatment and control areas. This finding is especially true for the models in which we select only few treatment and control areas. With only one randomly selected treatment (control) area compared to all control (treatment) areas, there is no apparent clustering of the point estimates, indicating a significant degree of area specific shocks and / or heterogeneity for the policy effect across the treated areas (upper left). With two randomly drawn treatment or control areas, the distribution of the probability of obtaining a point estimate near to the average treatment effect significantly increases even though only a small proportion of the estimates falls within two standard error lengths of the benchmark estimate (upper right). With five treatment or control groups there is a relatively well-behaved probability distribution centered around the average treatment effect, with the majority of individual estimates being within two standard error lengths (middle left). Not surprisingly, the variation is further reduced as more areas are considered.

When treatment and control areas are randomly drawn simultaneously, the probability distributions start to exhibit a reasonable shape once at least five treatment and control areas are considered (bottom left), although the results still show a remarkable degree of variation across the iterations. The variation decreases substantially as the number of treatment and control areas is increased. With fifteen treatment and control areas, the mean of the point estimates is very close to the benchmark model (using all 22 treatment and 22 control areas). Also, the standard deviation of the estimates is very close to the standard error estimated in the benchmark model.

We conclude that the reliability for the estimate of the impact of place-based policies critically depends on the number of treatment and control areas available. Our results suggest that the stability of the results increases sharply once at least five treatment and five control areas are available. 
Fig. A4. Evaluation of treatment heterogeneity

Separately varying treatment \& control groups

1 random area selected

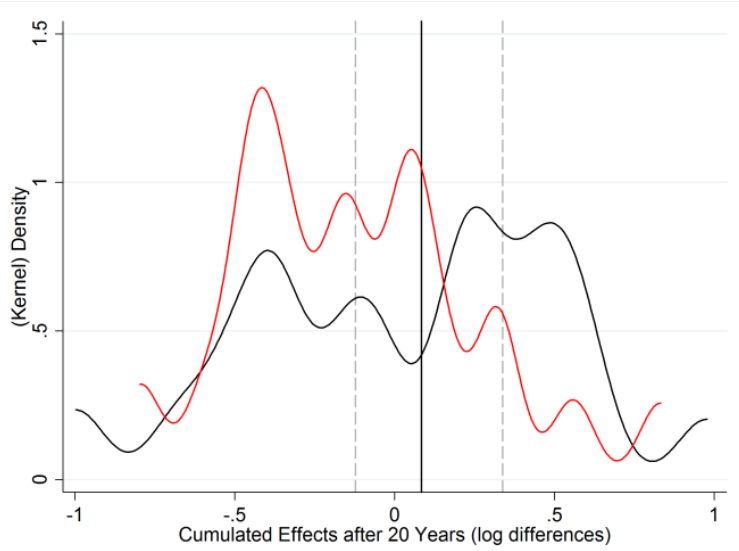

5 random areas selected

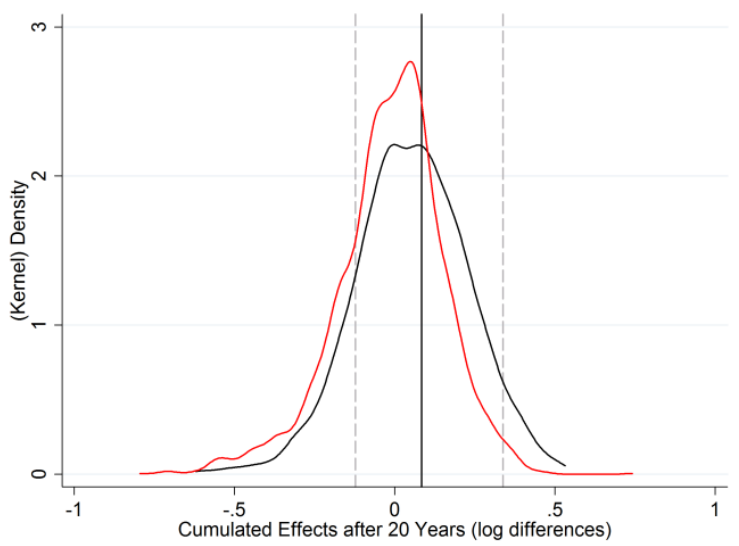

2 random areas selected

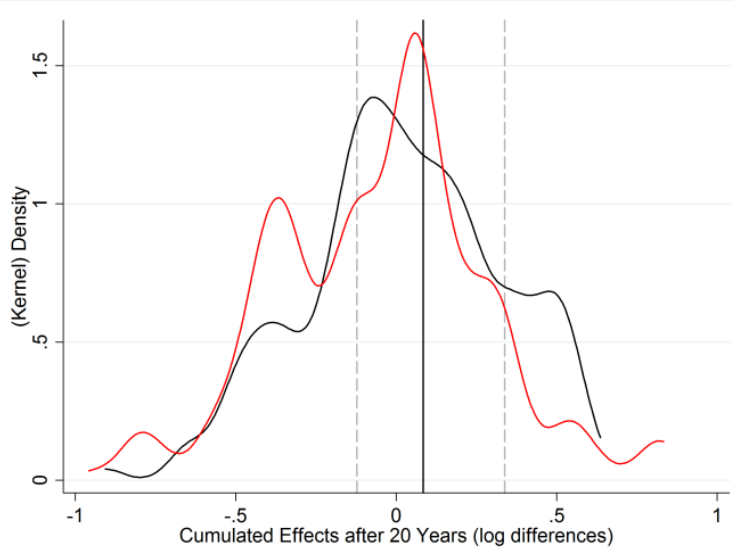

15 random areas selected

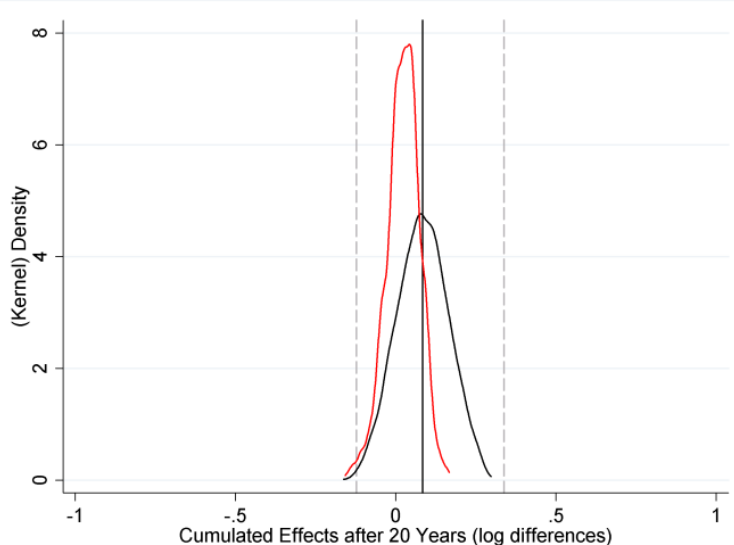

Simultaneously varying treatment \& control groups

5 random areas selected

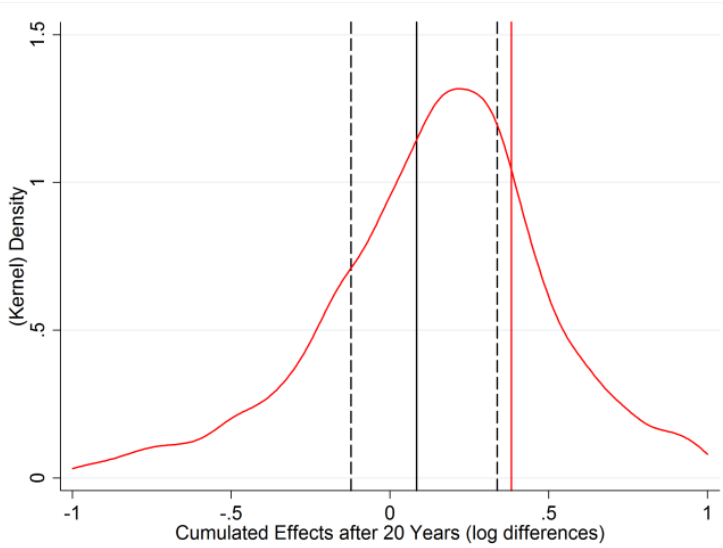

15 random areas selected

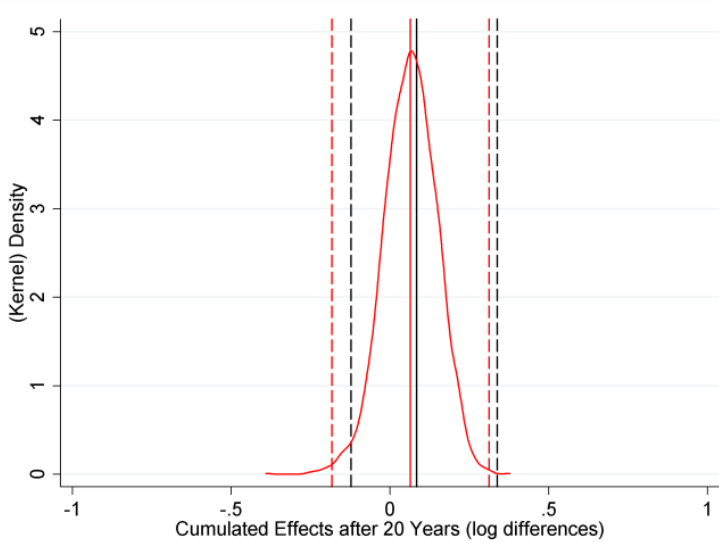

Notes: In the upper two rows, black (red) solid lines depict the kernel density of cumulated effects when varying the number of renewal (investigation) areas. The black vertical lines depict the cumulated effect of our benchmark model (solid) plus/minus two standard error lengths (dashed). 


\section{Treatment heterogeneity}

In the main paper, we focus on estimating the average policy effect across all treated renewal areas, which strengthens the identification by using all available information. As we observe transactions in at various distances to the CBD, at locations with significantly different amenity endowments, and in different city districts, we can use the available variation to credibly control for temporal trends that are correlated with these characteristics. At the same time, Figure A4 (upper left, black solid line) reveals a large degree of treatment heterogeneity across renewal areas. It should be noted that the variability of the results may be amplified by the relatively demanding specification, which may be particularly sensitive to reductions in the degrees of freedom.

Our recommended estimates for treatment effects by renewal area use a less demanding specification. To save degrees of freedom, we do not estimate our parametric treatment function from the main paper, but the difference in the (adjusted) average price level before designation and after 15 years, which is roughly the average runtime of the renewal areas. Dropping all transactions occurring within the first 15 years after designation, we estimate the long-run effect of designation using a simplified version of the benchmark model that omits the trend interaction effect. We compare the transactions in each renewal area separately against a specific control group, all transactions within a 500 to 3000 meter buffer area around the renewal area. Transactions in other renewal areas and in a $500 \mathrm{~m}$ buffer around other renewal areas are excluded from a renewal area specific control group. We control for time varying effects with respect to distance to CBD (interacted with the post treatment indicator) and the amenity density (interacted with the post treatment indicator). We also include the typical area floor space index, the unemployment rate, and the share of foreigners as covariates. The individual treatment results from the separate regressions by renewal area are summarized in Table A11.

Despite the modifications we recommend that the individual estimates be interpreted with care due to the relatively small number of observations in some cases and the arguably less comprehensive control for patio-temporal trends. Any apparent pattern will therefore only provide a tentative indication of the determinants that drive treatment heterogeneity. Overall, the estimates suggest a significant degree of treatment heterogeneity, which appears worth being investigated in more detail in future research. Potential sources of this heterogeneity include area-specific, heterogeneous policy targets that (lo- 
cal) decision makers, principal agents, and inhabitants agreed on, ${ }^{2}$ the ratio of renovated houses in the area, impacts of improvements like traffic calmings, (re)construction of playgrounds and parks, greenings, and establishment of local community centers (potentially depending on religious affiliations). Finally the significantly positive appreciation rates may also reflect a tendency toward gentrification that is unrelated to the policy and has not been captured by the time-varying effects of distance to the CBD and amenity density.

\section{Tab A11.Area specific effects}

\begin{tabular}{|c|c|c|c|c|c|c|c|c|}
\hline Area & $\begin{array}{l}\text { Cumula } \\
\text { formed }\end{array}$ & $\begin{array}{l}\text { Cumulated } \\
\% \text { change }\end{array}$ & $\begin{array}{l}\text { (Cumula } \\
\text { ces after } \\
\text { Average } \\
\text { appr. } \\
\text { rate }\end{array}$ & $\begin{array}{l}\text { d log-level t } \\
\text { years) }\end{array}$ & $\begin{array}{c}\text { Standard } \\
\text { error }\end{array}$ & $P$ value & t-stat & $\begin{array}{c}\text { Sub-sample } \\
\text { size }\end{array}$ \\
\hline & \multicolumn{8}{|c|}{ Internal effects } \\
\hline 1 & Helmholtzplatz & $40.32 \%$ & $2.28 \%$ & 0.339 & 0.372 & 0.369 & 0.909 & 521 \\
\hline 2 & Spandauer Vorstadt & $121.36 \%$ & $5.44 \%$ & $0.795 * * *$ & 0.160 & 0.000 & 4.968 & 609 \\
\hline 3 & Kollwitzplatz & $74.84 \%$ & $3.79 \%$ & $0.559 * * *$ & 0.201 & 0.008 & 2.773 & 588 \\
\hline 4 & Samariterviertel & $-11.96 \%$ & $-0.85 \%$ & -0.127 & 0.253 & 0.618 & -0.504 & 483 \\
\hline 5 & Altstadt Kiez Vorstadt & $-12.70 \%$ & $-0.90 \%$ & -0.136 & 0.097 & 0.187 & -1.407 & 603 \\
\hline 6 & Niederschöneweide & $-55.24 \%$ & $-5.22 \%$ & $-0.804 * * *$ & 0.163 & 0.000 & -4.918 & 503 \\
\hline 7 & Teutoburger Platz & $81.80 \%$ & $4.07 \%$ & 0.598 & 0.478 & 0.219 & 1.250 & 584 \\
\hline 8 & Winsstrasse & $56.27 \%$ & $3.02 \%$ & $0.446 * * *$ & 0.160 & 0.008 & 2.796 & 414 \\
\hline 9 & Warschauer Strasse & $2.40 \%$ & $0.16 \%$ & 0.024 & 0.219 & 0.915 & 0.108 & 548 \\
\hline 10 & Komponistenviertel & $0.12 \%$ & $0.01 \%$ & 0.001 & 0.201 & 0.995 & 0.006 & 552 \\
\hline 11 & Traveplatz Ostkreuz & $44.00 \%$ & $2.46 \%$ & $0.365 * *$ & 0.146 & 0.018 & 2.503 & 484 \\
\hline 12 & Wollankstrasse & $27.09 \%$ & $1.61 \%$ & $0.240 *$ & 0.131 & 0.079 & 1.826 & 709 \\
\hline 13 & Beusselstrasse & $-27.12 \%$ & $-2.09 \%$ & $-0.316^{* *}$ & 0.117 & 0.012 & -2.704 & 453 \\
\hline 14 & Rosenthaler Vorstadt & $359.54 \%$ & $10.70 \%$ & $1.525^{* * *}$ & 0.277 & 0.000 & 5.501 & 575 \\
\hline 15 & Kaskelstrasse & $3.97 \%$ & $0.26 \%$ & 0.039 & 0.108 & 0.721 & 0.362 & 413 \\
\hline 16 & Weitlingstrasse & $-17.77 \%$ & $-1.30 \%$ & -0.196 & 0.116 & 0.104 & -1.680 & 462 \\
\hline 17 & Wederstrasse & $-40.02 \%$ & $-3.35 \%$ & $-0.511^{*}$ & 0.264 & 0.066 & -1.934 & 591 \\
\hline 18 & Boetzowstrasse & $25.81 \%$ & $1.54 \%$ & $0.230 *$ & 0.130 & 0.088 & 1.766 & 374 \\
\hline 19 & Oberschöneweide & $-6.49 \%$ & $-0.45 \%$ & -0.067 & 0.224 & 0.767 & -0.300 & 546 \\
\hline 20 & Stephankiez & $23.58 \%$ & $1.42 \%$ & $0.212 * *$ & 0.091 & 0.026 & 2.340 & 477 \\
\hline
\end{tabular}

Notes: ${ }^{*} p<0.1,{ }^{* *} p<0.05,{ }^{* * *} p<0.01$. Estimates refer to the conditional difference in mean prices before and 15 years after designation. The last column displays the number of observations included in each regression, including the treatment and control group. Due to only a relatively small number of observations we omit the results for the two renewal areas Soldiner Strasse and Kottbusser Damm Ost.

2 Note that the rate of home-owners may differ from area to area. On the impact of differing homeownership rates on the process of political decision making see Fischl (2001) and Ahlfeldt and Maennig (Ahlfeldt \& Maennig, 2013). 


\subsection{Aggregated impact (back of the envelope)}

To perform a back on the envelope calculation of the effectiveness of renewal policies, we draw on Table 1 in the main paper. Column 3 may be regarded as an upper bound because it imposes the strong assumption that, in the absence of policy treatment, the investigated areas would have followed exactly the same trend as the treated areas. By this assumption, we e.g. disregard potential "picking the winners"-effects by policy makers. Column 5 may be regarded as the lower bound because it allows for heterogeneous trends with respect to selected location characteristics. It provides an underestimate of the total effect if the changes in the perceived value of the determinants, which we regard as exogenous, are caused by the renewal policy. In each case, the policy effect is reflective of both an increase in property value due to an upgrade of the internal structure of an individual property and potential housing externalities arising from the mutual dependencies across properties. Our estimates can form the basis for a simple back of the envelope calculation of the total increase in property value caused by the policy, which is simply the total 2012 property value in the renewal areas multiplied by the percentage figure that is attributable to the policy according to our estimates. Table A12 provides the results which suggest that, for each of the $€ 1.8$ bill. invested, approximately $€ 0.35$ - $€ 1.8$ are generated in terms of property value, where - notably - the lower bound is not based on an estimate that is not significantly different from zero. The non-educated mean of the two values is close to one - public investments cause a simple rent shift from taxpayers to some individuals with no welfare gain. The simple calculations reinforce our skepticism regarding the multiplier effects that operate through housing externalities caused by the policy in Berlin. 


\section{Tab A12.Back of the envelope calculation}

\begin{tabular}{|c|c|c|c|c|}
\hline Area & Name & Average price & Properties & Property value \\
\hline 1 & Helmholtzplatz & 1445110 & 560 & $€ 809,261,600.00$ \\
\hline 2 & Spandauer Vorstadt & 3279287 & 632 & $€ 2,072,509,384.00$ \\
\hline 3 & Kollwitzplatz & 1917316 & 476 & $€ 912,642,416.00$ \\
\hline 4 & Samariterviertel & 1118928 & 263 & $€ 294,278,064.00$ \\
\hline 5 & Altstadt Kiez Vorstadt & 865380.4 & 225 & $€ 194,710,590.00$ \\
\hline 6 & Niederschöneweide & 625492.2 & 97 & $€ 60,672,743.40$ \\
\hline 7 & Teutoburger Platz & 1426790 & 316 & $€ 450,865,640.00$ \\
\hline 8 & Winsstrasse & 1806810 & 219 & $€ 395,691,390.00$ \\
\hline 9 & Warschauer Strasse & 1239994 & 227 & $€ 281,478,638.00$ \\
\hline 10 & Komponistenviertel & 859561.3 & 477 & $€ 410,010,740.10$ \\
\hline 11 & Traveplatz Ostkreuz & 1513061 & 204 & $€ 308,664,444.00$ \\
\hline 12 & Wollankstrasse & 1190595 & 338 & $€ 402,421,110.00$ \\
\hline 13 & Beusselstrasse & 1733452 & 93 & $€ 161,211,036.00$ \\
\hline 14 & Rosenthaler Vorstadt & 1131136 & 373 & $€ 421,913,728.00$ \\
\hline 15 & Kaskelstrasse & 528402.7 & 248 & $€ 131,043,869.60$ \\
\hline 16 & Weitlingstrasse & 1370382 & 331 & $€ 453,596,442.00$ \\
\hline 17 & Wederstrasse & 508517.7 & 233 & $€ 118,484,624.10$ \\
\hline 18 & Boetzowstrasse & 1314302 & 191 & $€ 251,031,682.00$ \\
\hline 19 & Oberschöneweide & 719929.4 & 255 & $€ 183,581,997.00$ \\
\hline 20 & Soldiner Strasse & 1239714 & 11 & $€ 13,636,854.00$ \\
\hline 21 & Kottbusser Damm Ost & 2021468 & 21 & $€ 42,450,828.00$ \\
\hline 22 & Stephankiez & 812702.8 & 54 & $€ 43,885,951.20$ \\
\hline \multirow{2}{*}{\multicolumn{4}{|c|}{$\begin{array}{r}\text { Total value: } \\
\text { Lower bound impact estimate }(7.33 \% \text {, Table } 1 \text {, model (5) }\end{array}$}} & $€ 8,414,043,771.40$ \\
\hline & & & & $€ 652,929,796.66$ \\
\hline \multicolumn{4}{|c|}{ Upper bound impact estimate ( $49.79 \%$, Table 1 , model $3 a)$} & $€ 3,414,418,962.43$ \\
\hline
\end{tabular}

Notes: The employed transaction prices are in 2012 Euros. 


\section{Literature}

Ahlfeldt, G. M., \& Maennig, W. (2013). Homevoters vs. Leasevoters: A Spatial Analysis of Airport Effects. CESifo Working Paper Series 4301. CESifo Group Munich.

Fischel, F. A. (2001). The Homevoter Hypothesis (Vol. Cambridge, MA.): Harvard Univ. Press.

Leuven, E., \& Sianesi, B. (2003). PSMATCH2: Stata module to perform full Mahalanobis and propensity score matching, common support graphing, and covariate imbalance testing (Version S432001): Boston College Department of Economics.

Rosenbaum, P. R., \& Rubin, D. B. (1983). The Central Role of the Propensity Score in Observational Studies for Causal Effects. Biometrika, 70(1), 41-55.

Rosenbaum, P. R., \& Rubin, D. B. (1985). Constructing a Control Group Using Multivariate Matched Sampling Methods That Incorporate the Propensity Score. American Statistician, 39(1), 33-38.

Senatsverwaltung für Stadtentwicklung Berlin. (2006). Urban and Environmental Information System. Berlin. 


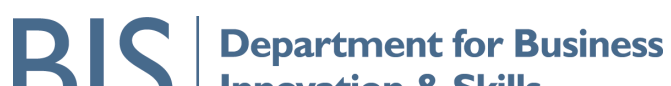 BIS}

\section{Spatial Economics Research Centre (SERC)}

London School of Economics

Houghton Street

London WC2A 2AE

Tel: 02078523565

Fax: 02079556848

Web: www.spatialeconomics.ac.uk

SERC is an independent research centre funded by the Economic and Social Research Council (ESRC), Department for Business Innovation and Skills (BIS) and the Welsh Government. 